Article

\title{
Copernicus User Uptake: From Data to Applications
}

\author{
Lorenza Apicella (D), Monica De Martino *(D) and Alfonso Quarati (D)
}

check for

updates

Citation: Apicella, L.; De Martino, M.; Quarati, A. Copernicus User Uptake: From Data to Applications. ISPRS Int J. Geo-Inf. 2022, 11, 121. https:// doi.org/10.3390/ijgi11020121

Academic Editor: Wolfgang Kainz

Received: 15 November 2021

Accepted: 4 February 2022

Published: 9 February 2022

Publisher's Note: MDPI stays neutral with regard to jurisdictional claims in published maps and institutional affiliations.

Copyright: (C) 2022 by the authors. Licensee MDPI, Basel, Switzerland. This article is an open access article distributed under the terms and conditions of the Creative Commons Attribution (CC BY) license (https:// creativecommons.org/licenses/by/ $4.0 /)$.

\author{
Institute for Applied Mathematics and Information Technologies-National Research Council, 16146 Genoa, Italy; \\ lorenza.apicella@ge.imati.cnr.it (L.A.); alfonso.quarati@ge.imati.cnr.it (A.Q.) \\ * Correspondence: monica.demartino@ge.imati.cnr.it
}

\begin{abstract}
The European Programme Copernicus, one of the principal sources of free and open Earth Observation (EO) data, intends to sustain social and economic advancements to the European Union. To this end, User Uptake initiatives have been undertaken to increase Copernicus awareness, dissemination, and competencies, thus supporting the development of downstream applications. As part of the activities performed in the EO-UPTAKE project, we illustrate a set of application scenario workflows exemplifying usage practices of the data and tools available in the Copernicus ecosystem. Through the know-how gained in the design and development of the application scenarios and the bibliographic analysis on downstream applications, we discuss a series of practical recommendations to promote the use of Copernicus resources towards a wider audience of end-users boosting the development of new EO applications along with some advice to data providers to improve their publication practices.
\end{abstract}

Keywords: Copernicus Programme; user uptake; sentinels data; workflow

\section{Introduction}

In December 2019, the European Environment Agency (EEA) (https: / www.eea.euro pa.eu/, accessed on 10 November 2021), in the "European Environment-State and Outlook 2020" (SOER) report [1], detailed the scale and urgency of Europe's current environmental, climate and sustainability challenges. In responses to these challenges, the European Commission (EC) adopted the European Green Deal (EGD) road map document [2] for the EU's climate action plan. The road map provides a framework for ambitious actions and measures towards European sustainability.

Amongst these measures, the EU suggested the adoption of a new eighth Environment Action Programme [3] aiming to set out the direction for EU environmental and climate policy action up to 2030, and to support the implementation and the effective enforcement of environmental and climate policies and legislation to achieve the 2030 greenhouse gas emission reduction target and climate neutrality by 2050. Recognizing the role of data, EGD recommends to exploit the potential of digital technologies and data to support environmental policy and outlines the use of satellite observations as a strategic enabler to reach its objectives.

Specifically, EEA is requested to support the Commission in improving the availability and relevance of data and knowledge, among others, by "integrating data on environmental, social and economic impacts, and exploiting fully other available data, such as those delivered by Copernicus" ([3], p. 13). Accordingly, as one of EGD main goals is to achieve zero net emissions of greenhouse gases in 2050, as well as protecting, conserving, and enhancing the EU's natural capital, the European Earth observation program Copernicus (https: / / www.copernicus.eu/, accessed on 10 November 2021) has a crucial role in implementing and monitoring these key objectives.

Launched in 1998 by the EC and the European Space Agency (ESA), Copernicus provides free access to near real-time data, collected by dedicated EO satellites called Sentinels, in situ observations, and a set of core information services essential to help manage 
global security and the environment. Its continuity of observations with high-frequency satellite images for atmospheric, oceanic, and terrestrial monitoring substantially benefits socio-economic as well as smart and sustainable growth, promoting the development of innovative solutions in many sectors, prompting the realization of the EGD priorities for implementing the EU climate plan.

While the provision of Copernicus data and the implementation of related services have advanced enormously, it became urgent to support the users and uptake of Copernicus services and data-sets [4,5]. In fact, as in the case of other public Open Data resources [6-10], Copernicus data and information remain under-exploited, and further efforts are needed to engage users [11].

Acknowledging this issue, the EC delivered, in 2016, a Space Strategy for Europe to encourage the uptake of space services and data [4] and to support research, innovation, and the development of skills for space and EO. Currently the need for uptake action is still explicitly recommended in the EEA-Eionet Strategy 2021-2030 [12].

The EU-funded Italian regional project EO-UPTAKE (www.gisig.eu/projects/eoup take/, accessed on 10 November 2021), in line with the EC promoted initiatives supporting the use of Copernicus data and services among a broader range of downstream sector's user communities, aims to increase the diffusion of Information Technology (IT) and Remote Sensing (RS) knowledge and skills regarding the Copernicus ecosystem in the Ligurian production framework.

By bridging the worlds of research and the Small and Medium Enterprises (SMEs) and utilities involved in the environmental sector, EO-UPTAKE aims to disseminate the capacity for innovation and technology transfer towards a productive system in which companies and public bodies can benefit from Copernicus resources in the implementation of innovative and shared territorial applications.

Based on the ongoing EO-UPTAKE activities, the paper presents a double contribution. Through the discussion of four application scenarios, we exemplify how and with what data and tools users with primary IT and RS skills can benefit the Copernicus ecosystem to develop applications of immediate practical use.

Furthermore, in the light of the experience gained in developing these scenarios and based on a review of the literature on the downstream applications in different sectors, we supply a set of recommendations to make users aware of the potentiality of the Copernicus resources and to encourage their use and integration with other Open Data sources as well as advice to data providers to improve their publication practices.

\section{Copernicus Background}

In the Copernicus program data value chain, i.e., the process of creating, collecting, publishing, and adopting data, the downstream sector plays the essential role of transforming the spatial data produced by satellite platforms into EO products and services directly usable by the end-users [13]. The actors involved in this transformation process, also called intermediate users, are generally experts in EO [14], such as "Value-Added Services (VAS) and geo-information companies, whose core business is to process satellite EO data and turn it into geo-information products" ([13], p. 17).

End-users may be "the citizens benefiting from a better air quality or reduced pollution of groundwater" ([13], p. 48) as well as the "institutional actors (e.g., meteo agencies, emergency services, forestry offices, scientific laboratories...) and private ones" ([15], p. 9). Those users' main activity is usually not centered on $\mathrm{EO}$ and, not generally being experts in EO, they rely on intermediate users for accessing geo-referenced information as relevant inputs for their business.

In some cases, however, end-users with IT skills, but not EO experts, could combine, through their in-house resources, the obtained geospatial products, with their "relevant sources of information for their business (e.g., the type of crops, the function of the infrastructure, the profile of their customers, the relationships of their agents, etc.)" ([14], p. 14). 
On the other hand, users "with at least some form of training in Earth observation/geoinformation" ([5], p. 12) could use Copernicus products and services to implement simple application scenarios for studying and analyzing a particular terrestrial phenomenon, without necessarily having to outsource the task to intermediate IT companies [15]. In the following, we mainly address these two types of end-users to provide them with some recommendations that we matured during the study and hands-on activities with tools and products of the Copernicus ecosystem used to develop application scenarios in the course of EO-UPTAKE.

\subsection{Sentinel Satellites and Copernicus Ecosystem}

The Copernicus space component consists of two types of satellites: the EU-owned Sentinels constellation, which has been specifically designed to meet the needs of the Copernicus services and their users, and missions from other space agencies, called Contributing Missions, which exist independently and deliver complementary data. ESA and the European Organisation for the Exploitation of Meteorological Satellites (EUMETSAT (https:/ / www.eumetsat.int, accessed on 10 November 2021)) are in charge of the development of the program's space component.

Currently, three Sentinel missions, namely Sentinel-1 (S-1A, S-1B), Sentinel-2 (S-2A, S-2B), and Sentinel-3 (S-3A, S-3B), plus two single satellites, Sentinel-5 Precursor (S-5P) and Sentinel-6 Michael Freilich (S-6), are in orbit. The latter, being a joint partnership between the National Aeronautics and Space Administration (NASA) and ESA after its twin will be launched in 2025 and will "measure sea level down to the centimeter for more than 90\% of the world's oceans" (https:/ / www.nasa.gov/sentinel-6/overview, accessed on 10 November 2021). In the next few years, two missions, Sentinel-4 (S-4) and Sentinel-5 (S-5), targeting monitoring air quality, will be sent in orbit, extending the constellation. Table 1 synthesises Sentinel main features.

Table 1. Sentinel features: launch date, sensor and acquisition mode, spatial resolution, revisit time, and operational domain.

\begin{tabular}{|c|c|c|c|c|}
\hline Sentinel & Sensor & Resolution & Revisit & Domain \\
\hline S-1A/B (2014/16) & $\begin{array}{c}\text { Synthetic Aperture Radar } \\
\text { (SAR) }\end{array}$ & $4-40 \mathrm{~m}$ & 6 days & $\begin{array}{l}\text { Oceans, ice and land, } \\
\text { emergency }\end{array}$ \\
\hline S-2A/B (2015/17) & $\begin{array}{l}\text { HR Multi-spectral imagery } \\
\text { (MSI) }\end{array}$ & $10-60 \mathrm{~m}$ & 5 days & Land and vegetation cover \\
\hline S-3A/B (2016/18) & $\begin{array}{l}\text { Radar altimeter, Surface } \\
\text { Land Sea Temperature } \\
\text { Radiometer (SLSTR), Ocean } \\
\text { and Land Color Instrument } \\
\text { (OLCI) }\end{array}$ & $300-1200 \mathrm{~m}$ & $<2$ days & $\begin{array}{l}\text { Land-cover and ocean color } \\
\text { and reflectances, land and } \\
\text { sea temperature and } \\
\text { topography }\end{array}$ \\
\hline S-5P (2017) & $\begin{array}{l}\text { TROPOspheric Monitoring } \\
\text { Instrument (TROPOMI) }\end{array}$ & $7-68 \mathrm{~km}$ & 1 day & Global atmospheric pollution \\
\hline S-4 ( 2024) & $\begin{array}{c}\text { Ultraviolet-Visible-Near- } \\
\text { Infrared (UVN) Spectrometer } \\
\text { on Meteosat Third } \\
\text { Generation Sounder (MTG-S) }\end{array}$ & $8 \mathrm{~km}$ & $60 \mathrm{~min}$. & European air quality \\
\hline S-5 ( 2024) & $\begin{array}{l}\text { Spectrometer on MetOp } \\
\text { satellites }\end{array}$ & $7.5-50 \mathrm{~km}$ & 1 day & Global air quality \\
\hline S-6 (2020/ 25) & Radar altimeter & & 10 days & $\begin{array}{l}\text { Global sea-surface height, } \\
\text { oceanography, climate }\end{array}$ \\
\hline
\end{tabular}

Sentinel products are distributed using a SENTINEL-specific variation of the Standard Archive Format for Europe (SAFE (https: / / Earth.esa.int/SAFE/, accessed on 10 November 2021)) specification. The SAFE format has been designed to act as a common format for 
archiving and conveying data within ESA EO archiving facilities. The SENTINEL-SAFE format (https://sentinels.copernicus.eu/web/sentinel/user-guides/sentinel-1-sar/data-f ormats/safe-specification, accessed on 10 November 2021) wraps a folder containing image data in a flexible binary data format and product metadata in XML. This flexibility allows the format to be sufficiently scalable to represent all levels of SENTINEL products.

The directory folder contains a collection of information: a 'manifest.safe' file that holds the general product information in XML, subfolders for measurement datasets containing image data in various binary formats, a preview folder containing 'quicklooks' (in different formats for different missions), an annotation folder containing the product metadata in XML as well as calibration data, and a support folder containing the XML schemes describing the product XML or HTML preview. The folder's wrapped information varies according to the Sentinel mission and the pre-processing levels, and it is detailed in a 'data format' section of the Sentinel's user guide (https:/ / sentinels.copernicus.eu/web/ sentinel/user-guides, accessed on 10 November 2021).

Copernicus provides Sentinel products obtained by raw data processing at various levels, allowing users to choose the processing level best fitting their purposes. Different satellite missions present different classifications; however, in general pre-processing levels range from 0 to 4 , bringing different information along with each level. Level 0 products are raw data at full instrument resolution, while at higher levels the data are converted into more readily usable metrics and formats. Copernicus products are supplied in the following three processing levels:

- Level-0 data (L0), raw data. They are not not disseminated to all users.

- Level-1 data (L1), products derived by L0 pre-processing based on radiometric and geographic positioning corrections.

- Level-2 data (L2), products derived from L1 pre-processing, characterized by a scene classification. For S-2, an atmospheric correction is applied to the Top-Of-Atmosphere orthoimage and the main output is a Bottom-Of-Atmosphere corrected orthoimage (i.e., Level-2A). For S-3, the bands for sea surface temperature, land surface temperature, and fire radiative power are computed.

Copernicus also provides six core services (https://www.copernicus.eu/en/coper nicus-services, accessed on 10 November 2021) free of charge, which transform Sentinel products for six thematic areas (i.e., land, sea, atmosphere, climate change, emergency management and security) in ready-to-use information. The Copernicus Land Monitoring Service (CLMS) provides geographical information on land-cover and use for the development of applications in a wide range of areas, such as agricultural and food security, forest management, water management, nature conservation, and restoration.

The Copernicus Emergency Management Service (CEMS) encompasses an early warning component about risk assessments for floods and forest fires and a mapping component that provides map and geo-information resources for all types of natural and man-made disasters. The Copernicus Atmosphere Monitoring Service (CAMS) is at the forefront of the monitoring efforts through its data on $\mathrm{CO}_{2}$, such as global and regional forecasts and analyses of air concentrations, as well as monthly surface fluxes.

The Copernicus Marine Service (CMEMS) provides relevant information for the marine renewable energy sector, where information about ocean currents, waves, sea level, salinity, and temperature support the safer implementation of energy platforms at sea.

The Copernicus Security Service (CSS) focuses on crisis prevention, preparedness, and response in three domains: border surveillance, maritime surveillance, and support to EU External Action. It supports EU policies by providing information in response to security challenges, and its use is restricted to authorized users. The Copernicus Climate Change Service (C3S), provides authoritatively and quality-assured resources about the past, present, and future climate.

These services have subsequently reached different degrees of maturity as they have been released: in 2012 for CLMS and CEMS, in 2015 for CAMS and CMEMS, in 2017 for CSS, and in 2018 for C3S. Although these services partly bridge the gap between Copernicus 
data and end-users, "there is still, in most cases, a final step to be made by intermediate users to tailor solutions to end-users' needs" ([5], p. 12).

\subsection{Copernicus User Uptake}

The Copernicus program is expected to provide important strategic, social, and economic benefits to the EU. According to the latest EU report on the EO data market [14], the volume of data provided by Copernicus in 2019 was around 150 terabytes every day, with economic benefits estimated at $€ 16.2$ and $€ 21.3$ billion in the period 2018-2020, and a constantly growing number of users (currently 780,000). Notwithstanding these promises, as for other public and research Open Data [6,8], Copernicus data have value only if they are used across a wide range of applications in various thematic sectors to meet specific public or commercial needs, resulting in new opportunities for society and economy.

This fact is clearly expressed by the EC Communication on the Space Strategy for Europe that stated that "The potential of space solutions has not yet been fully exploited, and nor have the wider possibilities offered by space data" [4]. The number of heterogeneous EO resources supplied and the breadth of different user communities potentially interested require new skills to realize Copernicus's full potentials [16].

Copernicus user uptake activities are essential to maximizing the adoption of Copernicus resources. To this end, the EU report about Copernicus User Uptake [16] fosters an effective user engagement strategy for the Copernicus Programme, supporting an ecosystem of service providers, public or private, able to transform space data into accessible and usable information and promoting the use and uptake of Copernicus products, services, and good practices towards a wider users audience.

Accordingly, the Commission focused on three objectives: to increase awareness, to facilitate access to Copernicus resources, and to support downstream actors [13]. To meet these goals, the EC has promoted several initiatives, such as the Copernicus Relays and the Copernicus Academy Network [5,17]. Copernicus ambassadors ensure that information on the benefits and potential applications of the program are unleashed at the local level with Relays. On the other hand, the Copernicus Academy connects universities and research institutes with authorities and service providers, enhancing cooperation and research as well as preparing teaching and training materials.

The ambition of such initiatives is to boost "the development of the professional skills needed by the potential users of space data, where a key added value is given to merging skills and knowledge from different sectors, in particular, transversal skills such as IT, GIS and data-handling skills" ([5], p. 81).

Following this vein, EO-UPTAKE is a two-year project, started on November 2019 under the European Social Fund, Liguria Region 2014-2020, to support the EC strategy for User Uptake, by promoting the development and the dissemination of competencies related to Copernicus resources access and usage. EO-UPTAKE aims to strengthen the existing ecosystem of skills and foster the use and integration of such resources supporting innovative applications for end-users [18].

The project is centered on the training of a young environmental-sciences researcher for increasing their "technical skills regarding processing of RS data"([16], p. 440) and the subsequent transfer of their newly acquired competencies to potentially interested business end-users. Guided by those objectives, the project focuses on designing and implementing several exemplary application scenarios for the Agriculture, Forestry, Urban monitoring, and Natural disasters management user segments (also known as "value chains" [14], p. 27).

\section{Literature Review on Copernicus Downstream Applications}

To properly frame EO-UPTAKE's agenda, we analyzed the literature reporting the rationales and findings of Copernicus downstream applications in some of the promising user segments listed in the EC Copernicus Market report: Agriculture, Forestry, Urban monitoring, Coastal And Marine Exploitation and Preservation, Renewable Energies, Air 
quality management, and Management of natural disasters [14]. Table 2 synthesizes these contributions.

Agriculture - In the digital farming field, the work of Meier et al. [19] highlights the positive impacts of S-2 products for agricultural policies and smart farming applications, while the work of Lilienthal et al. [20] discussed the use of S-1 and S-2 products in the framework of a national project to involve farmers in digital farming, thus, to enhance and optimize agricultural production in Germany.

Drost et al. [21] presented a study on water and drought management, proposing an architecture for processing heterogeneous in situ and RS data enabling the integration of S-1 and S-2 with hydrological models for a water monitoring program involving the agricultural sector, water industry associations, and water suppliers.

Pulvirenti et al. [22] presented software designed for the systematic mapping of surface soil moisture using S-1 data, useful both for agriculture and Civil Protection tasks.

Wolanin et al. [23] and Vuolo et al. [24] presented two methods for crop monitoring and classification, exploiting, respectively, S-2 and Landsat (by NASA (https:/ / www. nasa.gov, accessed on 10 November 2021)) products to train a neural network model able to estimate a crop's gross primary production and S-2 optical images to assess the value of multi-temporal information for crop-type classification with the Random Forest Classifier [25].

Borgogno-Mondino et al. [26] proposed a method based on S-2 band computation for the detection of plastic-covered vineyards describing the different spectral responses of the vines compared to the uncovered ones.

Forestry - Li et al. in [27] discriminated treed and non-treed wetlands in boreal ecosystems using an S-1 product time-series. The authors explored the potential of within-year time series of C-band SAR observations from the data archive.

Tavares et al. [28] proposed methods for mapping land-cover and vegetation types with supervised classification algorithms on S- 2 images and performing biomass assessment according to S-1 data, while Ottosen et al. [29] proposed an unsupervised classification method on S-2 bands combination to assess tree coverage and forest mapping.

Palas et al. [30] employed a set of 15 vegetation indices to monitor tree-logging activities with S-2 optical images in Białowieża Forest, which is one of the last and largest remaining parts of the immense primeval forests in Europe.

Fonseca et al. [31] assessed the connectivity of riparian forests located in two distinct European bio-climatic regions when subject to a gradient of human disturbance, leveraging ready-to-use layers of 'actual riparian zones' and 'potential riparian zones', provided by CLMS and also comparing them with a 'Manual Riparian Zone' layer "produced by manually digitizing riparian vegetation patches over a very high-resolution World Imagery layer" ([31], p. 1).

Urban Monitoring - Since numerical modeling has become a valuable tool for analyzing detailed urban meteorology and to design urban climate services, works, such as that of Masson et al. [32], highlight the role of S-1, S-2 products, and the Copernicus Urban Atlas' resources (https:/ /land.copernicus.eu/local/urban-atlas, accessed on 10 November 2021), in their survey discussing climate model requirements and the recent developments in urban monitoring.

In the context of progressive urbanization and industrialization, the phenomenon of Urban Heat Islands (UHIs) was investigated with multiple perspectives [33] and by exploiting Copernicus S-3 products: Shumilo et al. [34] assessed the UHI effect for a single urban area considering green areas and population density distributions, while Sobrino et al. [35] proposed a new method to assess and compare UHI values of urban agglomerations around the world. Finally, Hidalgo Garcia et al. [36] determineed nightly factors that enhanced the UHI effects in different seasons.

Of particular interest, among RS urban planning applications, is the change-detection techniques for impervious surface monitoring: Lefebvre et al. [37] presented a data fu- 
sion method exploiting S-2 images to monitor urban areas that compute high resolution impervious layers, more updated than those provided by CLMS.

Shrestha et al. [38] employed S-1, S-2 products as input data for a land-cover supervised classification approach with the Random Forest classifier on Pakistani cities.

Coastal And Marine Exploitation And Preservation-Two applications addressing shipping and ice navigation were presented by Staneva et al. [39] and Bensoussan et al. [40]. The former explores the synergy between the CMEMS Monitoring and Forecasting Centres model outputs and the newly available Satellite products (S-3). The authors outlined how the joined satellite and model show the potential benefits of merging observational and Copernicus resources.

In [40], S-3 products were used for monitoring protected area SST (Superficial Sea Temperature) in the Mediterranean Region, by combining RS LST images and in situ monitoring systems. The authors posited that this combination "is a pillar to enhance our understanding of climate change impacts in coastal areas". S-3 Ocean and Land Color Instrument (OLCI) images were used as well by Van et al. [41] in the evaluation of the state of eutrophication of the North Sea, as they provide information on the color of the ocean used to identify the concentration of chlorophyll.

Poursanidis et al. [42] discussed the exploitation of S-2 products for coastal habitat mapping and satellite-derived bathymetry estimation using coastal aerosol band and providing maps of the dominant Mediterranean coastal marine habitats and the bathymetry in three survey sites in the East Mediterranean.

Minnett et al. [43] compared various sources of data for SST assessments and variations in relation to climate change, highlighting the advantages of the S-3 products.

Renewable Energy-Morin et al. [44], in collaboration with the European Centre for Medium-Range Weather Forecasts (ECMWF (https:/ / www.ecmwf.int/, accessed on 10 November 2021)), proposed an approach for resource management in a mountainous environment, for assessing "past and future operating conditions of ski resorts at the pan-European scale in the context of climate change", leveraging C3S resources. Alfadda et al. [45] proposed a irradiance forecast method using aerosol measurements by CAMS regarding solar energy production.

Air quality management-Huijen et al. [46] presented an air pollution monitoring study, analyzing the effects on air quality after a huge wildfire by exploiting CAMS resources. In the urban context, Baklanov et al. [47] presented an application supported by CAMS resources to build urban services meeting the special needs of cities through a combination of dense observation networks, high-resolution forecasts, multi-hazard early warning systems, and climate services for reducing emissions, thus, enabling the building of resilient, thriving sustainable cities.

Tchepel et al. [48] proposed two approaches to characterize urban background pollution levels for regional operational forecasts, exploiting CAMS freely available data on air pollution forecast from global and regional models and the "Chemical Transport Model" from the national forecast system of Portugal. Air quality monitoring was also performed in rural areas for specific climate-affecting compounds [49] and for the prediction and validation of forecasting for severe pollution events [50].

Management of Natural Disasters-Risk forecast applications target emergency situations, e.g., for the monitoring of landslides, exploiting S-1 SAR products, and interferometric change-detection techniques [51-53] or for investigating ground displacements due to changes in the permafrost layer [54].

The work of Carlà et al. [55] used Satellite SAR Interferometric techniques to identify precursors to catastrophic slope failures. Devries et al. [56], in the hydrology field, addressed the monitoring of almost-real-time flood events by integrating S-1 and Landsat products.

Wildfire hazards from heat stress were assessed by Vitolo et al. [57], leveraging CEMS data-sets for fire danger forecasts (produced by ECMWF, which has the role of computational forecast center of the CEMS), in order to launch a multi-hazard early warning system. 
Romero et al. [58] proposed a method for monitoring post-event floods and landslides along coastlines, leveraging the integration with Copernicus S-1 SAR products, together with ERS 1 and 2 satellite mission (https:/ / Earth.esa.int/eogateway/missions/ers/descrip tion, accessed on 10 November 2021) data.

Applications for rapid mapping and post event risk analysis were presented in Doxani et al. [59] and Caballero et al. [60]. The former's work realized flood mapping over agricultural areas, thus, improving the efficiency of the decision-making process on agricultural aid and reimbursement by reducing the number of in situ visits and minimizing the costs and delays of controls. S-1 and S-2 products were used to compare the area of interest (AOI) before and after flooding events. The reference for result evaluation was the corresponding information delivered by CEMS.

The latter specifically considers a 2019 flooding event in southern Spain, proposing a method for the creation of pre- and post-flood composite images obtained to identify change detection and mask water pixels with S-2 products.

Floods are monitored as well in the post risk forecasts application presented by Rossi et al. ([61], p. 145), where the authors proposed a set of automated services for weather forecasts, for providing "qualitative feedback for meteorological models, detecting the occurrence of an emergency event and extracting informative content that can be used to complement the situational awareness", leveraging the availability of weather forecasts, event detection techniques (supported by CEMS) and selective information retrieval from on-line social media.

A web application for the rapid mapping of floods was proposed by Da et al. [62], delineating flood-prone areas and reproducing the reference flood maps for the 64 subcatchments of the Po River. This application leverages the CLM service EU-DEM v1.0, a digital surface model available as a core service resource.

Table 2. Summary of the literature according to the studied applications and Copernicus resources used.

\begin{tabular}{|c|c|c|c|}
\hline User Segment & Paper & Application & Data/Services \\
\hline \multirow{7}{*}{ Agriculture } & Meier et al. [19] & digital and smart farming & $\mathrm{S}-2$ \\
\hline & Lilienthal et al. [20] & $\begin{array}{c}\text { digital farming with farmers } \\
\text { involvement }\end{array}$ & S-1, S-2 \\
\hline & Drost et al. [21] & $\begin{array}{l}\text { modeling architecture water } \\
\text { and drought management }\end{array}$ & S-1, S-2 \\
\hline & Pulvirenti et al. [22] & $\begin{array}{c}\text { operative water and drought } \\
\text { management }\end{array}$ & S-1 \\
\hline & Wolanin et al. [23] & $\begin{array}{l}\text { crop monitoring for primary } \\
\text { production assessments }\end{array}$ & S-2 \\
\hline & Vuolo et al. [24] & $\begin{array}{l}\text { crop monitoring for primary } \\
\text { production }\end{array}$ & S-2 \\
\hline & Borgogno-Mondino et al. [26] & crop monitoring for vineyards & S-2 \\
\hline \multirow{5}{*}{ Forestry } & Li et al. [27] & $\begin{array}{l}\text { resource mapping for } \\
\text { biodiversity monitoring }\end{array}$ & S-1 \\
\hline & Tavares et al. [28] & $\begin{array}{l}\text { resource mapping for biomass } \\
\text { assessments }\end{array}$ & S-1, S-2 \\
\hline & Ottosen et al. [29] & $\begin{array}{l}\text { resource mapping for tree } \\
\text { coverage }\end{array}$ & S-2 \\
\hline & Palas et al. [30] & $\begin{array}{l}\text { resource mapping with } \\
\text { vegetation indices }\end{array}$ & S-2 \\
\hline & Fonseca et al. [31] & $\begin{array}{l}\text { resource mapping for antropic } \\
\text { impact monitoring }\end{array}$ & CLMS \\
\hline
\end{tabular}


Table 2. Cont.

\begin{tabular}{|c|c|c|c|}
\hline User Segment & Paper & Application & Data/Services \\
\hline \multirow{6}{*}{ Urban Monitoring } & Masson et al. [32] & $\begin{array}{l}\text { urban planning, weather and } \\
\text { climate }\end{array}$ & $\begin{array}{c}\text { S-1, S-2, Copernicus Urban } \\
\text { Atlas }\end{array}$ \\
\hline & Shumilo et al. [34] & $\begin{array}{c}\text { urban planning for UHI local } \\
\text { management }\end{array}$ & 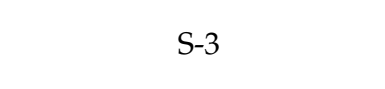 \\
\hline & Sobrino et al. [35] & $\begin{array}{c}\text { urban planning for UHIs } \\
\text { comparison }\end{array}$ & S-3 \\
\hline & Hidalgo Garcia et al. [36] & $\begin{array}{l}\text { urban planning forf UHI effect } \\
\text { management }\end{array}$ & S-3 \\
\hline & Lefebvre et al. [37] & $\begin{array}{l}\text { urban planning and } \\
\text { impervious surfaces }\end{array}$ & S-2 \\
\hline & Shrestha et al. [38] & $\begin{array}{l}\text { urban planning and land } \\
\text { cover classification }\end{array}$ & S-1, S-2 \\
\hline \multirow{5}{*}{$\begin{array}{c}\text { Coastal and Marine } \\
\text { Exploitation and Preservation }\end{array}$} & Staneva et al. [39] & $\begin{array}{l}\text { shipping and ice navigation } \\
\text { with in situ data }\end{array}$ & S-3, CMEMS \\
\hline & Bensoussan et al. [40] & $\begin{array}{l}\text { shipping and ice navigation } \\
\text { and protected areas } \\
\text { monitoring }\end{array}$ & S-3 \\
\hline & Van et al. [41] & $\begin{array}{l}\text { water quality and chlorophyll } \\
\text { indicator }\end{array}$ & S-3 \\
\hline & Poursanidis et al. [42] & $\begin{array}{l}\text { coastal management and } \\
\text { bathimetry mapping }\end{array}$ & S-2 \\
\hline & Minnett et al. [43] & $\begin{array}{c}\text { coastal management and SST } \\
\text { assessment }\end{array}$ & S-3 \\
\hline \multirow{2}{*}{ Renewable Energy } & Morin et al. [44] & $\begin{array}{l}\text { resources management and } \\
\text { climate change }\end{array}$ & C3S \\
\hline & Alfadda et al. [45] & $\begin{array}{l}\text { resources management for } \\
\text { solar energy production }\end{array}$ & CAMS \\
\hline \multirow{5}{*}{ Air quality management } & Huijen et al. [46] & $\begin{array}{l}\text { resources management and } \\
\text { wildfires }\end{array}$ & CAMS \\
\hline & Baklanov et al. [47] & $\begin{array}{c}\text { urban planning for smart } \\
\text { cities }\end{array}$ & CAMS \\
\hline & Tchepel et al. et al. [48] & $\begin{array}{l}\text { urban planning and } \\
\text { background pollution } \\
\text { monitoring }\end{array}$ & CAMS \\
\hline & De Blas et al. [49] & $\begin{array}{c}\text { air quality monitoring in rural } \\
\text { areas }\end{array}$ & \\
\hline & Eskes et al. [50] & $\begin{array}{l}\text { air quality monitoring and } \\
\text { forecasts }\end{array}$ & \\
\hline \multirow{12}{*}{ Management of Natural Disasters } & Handwerger et al. [51] & landslides risk forecasts & S-1 \\
\hline & Lesko et al. [52] & landslides risk forecasts & S-1 \\
\hline & Darvishi et al. [53] & landslides risk forecasts & S-1 \\
\hline & Rouyet et al. [54] & $\begin{array}{l}\text { ground displacements risk } \\
\text { forecasts }\end{array}$ & S-1 \\
\hline & Carlà et al. [55] & slope events risk forecasts & S-1 \\
\hline & Devries et al. [56] & floods risk forecasts & S-1 \\
\hline & Vitolo et al. [57] & wildfires risk forecasts & CEMS \\
\hline & Romero et al. [58] & $\begin{array}{l}\text { floods and landslides post } \\
\text { event risk analysis }\end{array}$ & S-1 \\
\hline & Doxani et al. [59] & $\begin{array}{l}\text { post event risk analysis in } \\
\text { agriculture }\end{array}$ & S-1, S-2 \\
\hline & Caballero et al. [60] & post floods event risk analysis & S-1 \\
\hline & Rossi et al. [61] & weather risk forecasts & CEMS \\
\hline & Da et al. [62] & rapid mapping for floods & CLMS \\
\hline
\end{tabular}




\section{Application Scenarios}

The primary activity of EO-UPTAKE concerns the definition and implementation of a set of application scenarios (ASs) with the key objective of developing competencies and skills in the use of Copernicus data and information to be transferred from the field of applied research to that of the productive sector.

In this perspective, a primary and fundamental role is played the self-training process, which took place after attending a couple of short specific courses on remote sensing and Copernicus data, carried out by the first author of the paper, a young researcher of environmental sciences but with little previous experience in the RS sector and satellite data. The design and implementation of several exemplary ASs constituted a very useful testbed for experimenting with the new notions acquired and for learning through hands-on training with the tools and data of the Copernicus ecosystem.

In the spirit of the EO-UPTAKE project of transferring the acquired skills to users in similar starting conditions (i.e., little or no RS and Copernicus skills) but with a sufficient background in Earth sciences, we present, in this section, the results of this training process, first providing an overview of the typical workflow of applications based on satellite data, a summary of the open-source tools used, and a sufficiently detailed description for each ASs of the main problems and the technical solutions adopted.

In light of the literature on downstream applications and the interests of the project partners, we present below the four implemented ASs relating to the Natural Disaster Management, Agriculture, Forestry, and Urban Monitoring user segments.

\subsection{Sentinel-Based Workflow}

The four application scenarios, namely AS1, AS2, AS3, and AS4, operationally share the same workflow structure, typical of many applications based on satellite products $[35,60,63,64]$ (Figure 1).

The first phase concerns the selection and download of the Sentinel products appropriate for the AS, followed by a pre-processing sequence of steps related to product quality check, resampling, and reprojection, which make the data ready for the core stage of the workflow: the processing that transforms the input products into the application-specific parameters. Integration with other third-sources data can occur either during the processing phase itself or when preparing the presentation of results.

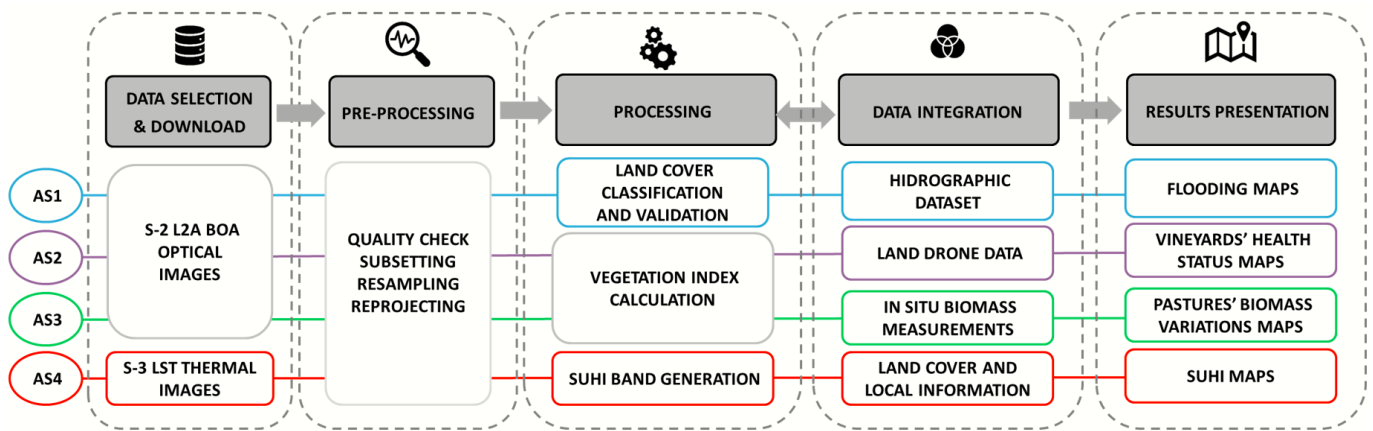

Figure 1. The schematized workflows of the four ASs highlighting the Sentinel data used, the processing goals, the data integration, and the result representation.

Sentinel products are downloadable through various access points, such as the Copernicus Open Access Hub and the Copernicus Space Component Data Access system provided by ESA, or the Copernicus Online Data Access point and the EUMETCast platform supplied by EUMETSAT. For our AS development, we selected the Copernicus Open Access Hub (https: / / scihub.copernicus.eu/, accessed on 10 November 2021), since it provides an immediate and easy interface to Sentinel products.

Although free of charge, and open, users must register on the Hub to download Copernicus data. Data remains online on the Hub for a period ranging from 6 months to 
1 year, after which it is archived according to the ESA rolling plan (https://sentinel.esa.i nt/documents /247904/3677657/4_DHUS+Evolution+for+On-line+Access.pdf, accessed on 10 November 2021). Once archived on the long-term archive (LTA), downloads can only take place after a request for restoration by users.

After logging into the Hub, the user can access the Sentinel products through an interactive graphical user interface that facilitates the identification of the target AOI and the setting of parameters (e.g., orbit, data format, and time window) to filter the product catalog based on user needs.

For each product matching the query, a preview is returned supplying metadata and a thumbnail image. Before downloading the whole product package, it is convenient to examine those thumbnails to check the presence of clouds that could affect the image processing. This check does not apply to the S-1 SAR products for which this is irrelevant. However, there are situations in which a cloud check may be more or less strict, thus, permitting the download of images even with partial clouds coverage. An example of this case, for S-2 products, is discussed in the following description of AS3.

For our AS1, AS2, and AS3 scenarios, we downloaded S-2 L2A products that provide $\mathrm{ECW} / \mathrm{JP} 2$ compressed images covering a square area of about $100 \times 100 \mathrm{~km}$, with a dimension of 10,980 pixels for each side. The single band images contain reflectance measurement of bands B02, B03, B04, and B08: Blue, Green, Red, and NIR respectively, with values from 0 to 65,535 and a spatial sampling of $10 \mathrm{~m}$. The other bands are supplied with a resolution ranging from $20 \mathrm{~m}$ to $60 \mathrm{~m}$. For AS4, we downloaded S-3 products providing SLSTR images which cover a swath width of $1420 \mathrm{~km}$ (nadir) $\times 750 \mathrm{~km}$ (backwards), with a spatial sampling of $500 \mathrm{~m}$ (for VIS and SWIR bands) and of $1 \mathrm{~km}$ (for MWIR and TIR bands).

Once downloaded, the selected images have to be pre-processed according to three tasks: (i) sub-setting, to crop the satellite image to the desired target area; (ii) re-sampling, to geometrically correct multi-size bands to a single-size band image; (iii) re-projection, to create an image with a projected Coordinate Reference System.

Concerning the AS processing phase, we leveraged the Sentinel Application Platform (SNAP) (https:/ / step.esa.int/main/toolboxes/snap, accessed on 10 November 2021) architecture, a processing software freely released by ESA for EO data management and analysis. SNAP also includes open-source toolboxes (https://sentinel.esa.int/web/sentine $1 /$ toolboxes0, accessed on 10 November 2021) for the scientific exploitation of the Sentinel products. The toolboxes consist of a collection of processing tools for S-1, S-2, and S-3 data, including product readers and writers for data display and analysis and supporting a vast archive of ESA and other missions data, thus allowing the exploitation of several types of satellite data.

As to data integration and results representation, we used QGIS (https:/ / www.qgis.o $\mathrm{rg} /$ en/site/, accessed on 10 November 2021), an open-source GIS that allows the analysis and possible reworking of the information calculated in the previous step to compose and export graphic maps. QGIS can georeference images and manage several data formats, including ESRI shapefiles, MapInfo and MicroStation file formats, and AutoCAD DXF. Web services, including Web Map Service (https://www.ogc.org/standards/wms, accessed on 10 November 2021) and Web Feature Service (https:/ / www.ogc.org/standards/wfs, accessed on 10 November 2021, are also supported for importing data from external sources.

\subsection{AS1-Flood-Risk Assessment in Rural Environment}

The ever-increasing impact on landscapes caused by human settlements and economic activities affects hydro-geological safety and, therefore, on risk assessment practices. Climate change is causing an increase in the intensity of rainfall and, therefore, of flooding phenomena, which threaten urban settlements, commercial activities, and all infrastructure located in hydro-geological risk areas [65,66]. Liguria is an area particularly sensitive to hydro-geological risk for both rural and urban areas [67-69]. 
The construction of artificial structures, like dams, affects the hydrological balance of the hydrographic systems within the basins and increases the hydro-geological risk. In particular, this is true for areas vulnerable to precipitation events of great intensity, such as Liguria, where catastrophic events of this kind have occurred in the last century [70,71]. Thus, monitoring the health of hydrographical basins is a matter of primary importance for civil protection, economic, and environmental purposes. Satellites images are used not only for emergency response, but also for risks forecasts and early warning operations [61,72].

\subsubsection{Objectives and Study Area}

Anticipatory measures, such as early warnings and forecasts, are the most efficient to mitigate the effects of natural disasters [14]. In this context, the AS1 integrates a landcover map, for an area characterized by an artificial dam, with information layers, such as flood-risk areas and hydrographic networks to highlight the land-cover classes with greater flood-risk.

The main AS1 goal was to produce a new land-cover map by processing an S-2 image with high spatial resolution $(10 \mathrm{~m})$ with a supervised classification technique. An alternative we initially considered was to use the Corine Land Cover maps (CLC_18), provided by the CLMS service, at the spatial resolution of $100 \mathrm{~m}$, updated every six years. We gave up on this option as the most recent available map is for 2018, preferring to produce an updated and higher resolution map.

We evaluated the effects of a possible dam break event in Lake Osiglia [ $44^{\circ} 17^{\prime} 52.72^{\prime \prime} \mathrm{N}$, $\left.8^{\circ} 11^{\prime} 56.44^{\prime \prime} \mathrm{E}\right]$, assessing the impacts on the different types of land-cover classes surrounding the lake. The study area around Osiglia lake is predominantly rural and not heavily populated: agricultural and tertiary activities are scattered with few urban agglomerations.

\subsubsection{Workflow}

According to the workflow of FigureGeneralPipeline, we started by selecting, from Copernicus Open Access Hub, a Sentinel (S-2 L2A) optical image of September 2020. After we pre-processed the selected RGB image, we applied the K-nearest neighbor (K-nn) classification algorithm, provided by SNAP for optical image processing for supervised classification purposes. We chose this algorithm because it offers a cutting-edge approach even for less experienced users.

In summary, K-nn ranks each pixel to the most common class among its training samples $\mathrm{k}$-nearest-neighbor (with $\mathrm{k}$ as a positive integer value that is typically small) [73]. Before running the algorithm, a manual selection step was required to identify some areas of the satellite image, considered as ground truth, according to a set of pre-defined classes.

We chose this set by following the CLC_18 nomenclature guidelines (https:/ / land.cop ernicus.eu/user-corner/technical-library/corine-land-cover-nomenclature-guidelines/doc s/pdf/CLC2018_Nomenclature_illustrated_guide_20190510.pdf, accessed on 10 November 2021) that define five main CLC classes: artificial surfaces (AS), agricultural areas (AA), forests and semi-natural areas (FA), wetlands (W), and water surfaces (WS) [74]. After this characterization, we applied the K-nn algorithm and saved the land-cover layers it produced as files with the extension '.BIGtiff' to be further processed and visualized via Q-GIS.

As the final step, we integrated the resulting land-cover map, with open hydrographic datasets generated by two free tools provided by the Brazilian 'Instituto Nacional de Pesquisas Espaciais' (INPE (https:/ / www.gov.br/inpe/pt-br, accessed on 10 November 2021)), one of the EO-UPTAKE's partners.

The distributed system TerraHidro [75,76] allows extracting drainage networks and basins from a regular grid Shuttle Radar Topography Mission - Digital Elevation Model (SRTM-DEM). We generated the raster map of the potential inundation by processing the drainage network of the AOI with the Height Above the Nearest Drainage algorithm (HAND) [77-79]. Integrating different types of data requires GIS skills for the management of the reference systems, which must be homogeneous. Notwithstanding, a tool like 
QGIS facilitated us in this task, allowing easy integration of the land-cover map with the INPE datasets.

Figure $2 \mathrm{~b}$ shows the integrated map of land-cover classes within the flood-risk areas (red line) with the anthropized areas potentially threatened by the presence of the artificial lake.

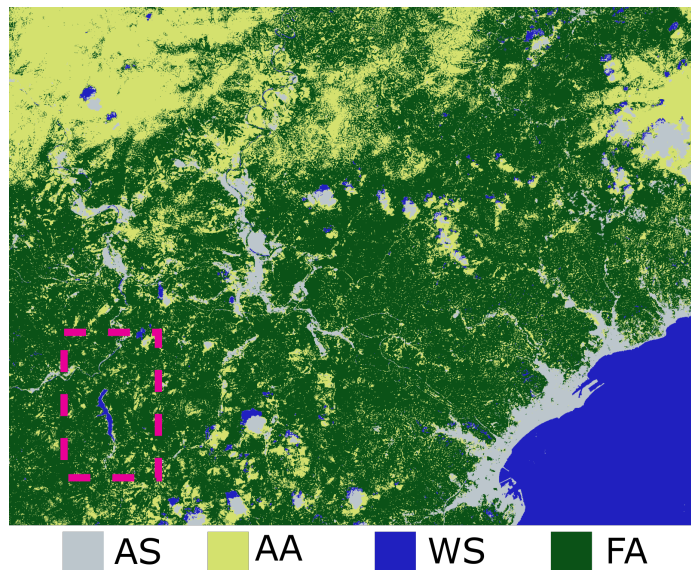

(a)

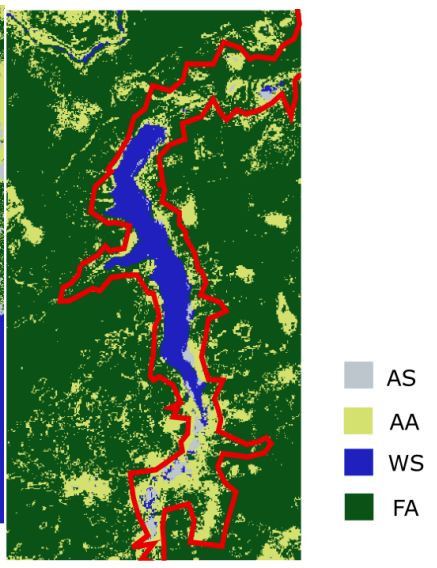

(b)

Figure 2. (a) Land-cover map for S-2 in 2020 of western Liguria: Osiglia lake (red square); (b) Integration of the flood-risk area downstream to the artificial Osiglia lake (red line) with the land-cover map in 2020 .

\subsection{AS2-Precision Farming for Vineyard Monitoring}

In the coming years, agriculture will have to tackle several significant pressures, including an increase in the world population, the threat of climate change, and the intensifying competition for increasingly scarce land, water, and energy resources [14]. Precision farming techniques allow more efficient culture management through EO practices.

High-resolution satellite images together with in situ sampled data represent a powerful resource that, through the employment of a specific application, could reach farmers and provide them with innovative farming techniques for different types of crops, including vineyards [80,81]. In this field, Copernicus Sentinel products are used and classified according to a set of known vegetation indices, thus, implementing nutrient management and water management [82].

\subsubsection{Objectives and Study Area}

AS2 aims at monitoring vineyards via RS for assessing the vines' state of health and supporting decisions and actions concerning biological and environmental protection. By calculating a vegetation index, i.e., the normalized difference vegetation index (NDVI), obtained by combining the percentage of refracted radiation of the different spectral bands of the RS signal, it is possible to get information on the overall status of the vegetation with a $10 \times 10 \mathrm{~m}$ spatial resolution.

The study area is located in the Ligurian province of La Spezia $\left[44^{\circ} 06^{\prime} 28.95^{\prime \prime} \mathrm{N}\right.$, $\left.9^{\circ} 49^{\prime} 43.94^{\prime \prime} \mathrm{E}\right]$, inside the plain of the Magra river, on the border with the province of Massa Carrara, where the vineyards are located in flat areas.

\subsubsection{Workflow}

We computed the vegetation index map of a selected September 2019 cloud-free S-2 L2A image containing some seaside vineyards in eastern Liguria. Vegetation absorbs and then re-emits solar radiation in various bands that are in different frequency ranges and wavelengths. The percentage of refracted radiation varies with plant health and water stress, which can be measured with vegetation indices.

The spectral response of vegetated areas presents a complex mixture of vegetation, soil brightness, environmental effects, shadow, soil color and moisture [83]. Specifically, for 
the NDVI in a field, areas with a significantly lower than average NDVI value may denote problems in vegetative development, for example, nutritional stress, parasitic attacks, hail damage, or frost.

NDVI also facilitates monitoring leaf area and canopy for crop protection, canopy adjustments, Summer pruning, and leaf area management, used to regulate canopy density and leaf distribution, promoting aeration to reduce the likelihood of diseases, and increasing berry sun exposure $[64,84]$. To identify the potentially problematic areas in each field, NDVI is computed according to Equation (1):

$$
\mathrm{NDVI}=(\mathrm{NIR}+\mathrm{RED}) /(\mathrm{NIR}-\mathrm{RED})
$$

To compute NDVI, we leveraged the 'Land Processor' toolbox provided by SNAP, offering an NDVI calculator which allows a guided approach for production of the index map. Once the index map is produced, it is then exported in QGIS and overlapped with the CLC_18 map provided by the CLMS service. This map includes the vineyard shapefiles for the AOI at $100 \mathrm{~m}$ spatial resolution (Class code 221), used for the identification of the vine-cultivated areas in the AOI (Figure 3a).

Figure $3 \mathrm{~b}$ shows the representation of the index obtained, with values ranging from 0 to 1 using a green scale palette, more intense for values close to 1 , and supplies users with a preliminary view of the state of vineyard health, highlighted by differences in the NDVI values.

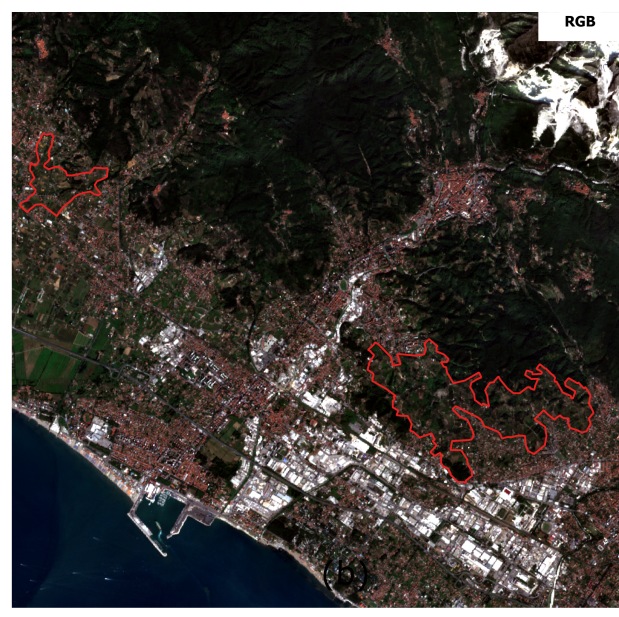

(a)

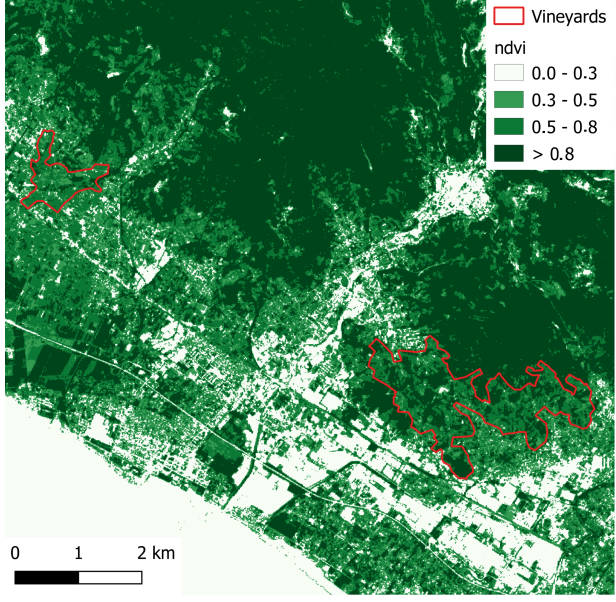

(b)

Figure 3. (a) The study area in real colors (RGB) and (b) the relative NDVI map. The red line delimits the areas intended for the cultivation of vines. NDVI values vary between 0 (absence of vegetation or not healthy vegetation) and 1 .

\subsection{AS3-Pasture Monitoring Tool for Sustainable Management}

Shifts in the timing and frequency of climate extremes, such as drought and heatwaves, can generate sustained transformations in ecosystem functions with important ecological and economic impacts for lands and pastures [85]. The soils are under increased pressure due to agriculture, forestry, grazing, and urbanization intensification.

The adoption of good practices for sustainable soil management is essential to reverse this tendency to degradation, as well as to guarantee food security and to protect the provision of several ecosystem services associated with the soil [86]. RS from aircraft or satellites was shown to be an effective method for monitoring vegetation in a range of environments [87]. 


\subsubsection{Objectives and Study Area}

The AS3 aims to evaluate pasture health status for Summer 2020 using satellite products in a mountainous area, by means of a spectral vegetation index and its variations across different months, to support sustainable pasture monitoring and management. The study area is located in the Paneveggio-Pale di San Martino natural park, a protected natural area of Trentino-Alto Adige, at an altitude ranging from 1100 to a maximum $3200 \mathrm{~m}$ asl, established by the Autonomous Province of Trento in 1967.

Its purpose is to protect the natural and environmental characteristics, to promote the scientific study and social use of environmental assets. The area has a complex orography that contains ecosystems of particular environmental value, sustaining a synergy with agricultural and pastoral activity. Satellite monitoring is an innovative tool that facilitates the management of these resources that men have exploited for centuries.

\subsubsection{Workflow}

In this scenario, considering the characteristics of the AOI, its small size (a few kilometers), and its tendency to be climatically predisposed to the formation of "spot" clouds during the day in summer, we did not initially exclude all images with cloudiness but only those affected by clouds more markedly.

Thus, we pre-selected, before downloading, a set of nine S-2 images containing the AOI relating to the period June-September 2020. After being downloaded, we thoroughly analyzed those nine images to keep only the cloud-free ones in the pasture areas of the Paneveggio park. This further check led to identifying four images, one per month, that we subsequently pre-processed.

After pre-processing, for each monthly image, we performed the thematic land processing by calculating the NDVI index via the toolbox available on SNAP. The resulting index values were exported in bigTIFF format on QGIS, where clipping with the shapefile of the Paneveggio grazing areas (www.parcopan.org/ente-parco/il-piano-del-parco/gli-s hapefiles-del-piano/, accessed on 10 November 2021) and the chromatic representation of NDVI on a scale of greens was carried out. As the last step, we calculated the inter-monthly variation percentage represented in Figure 4.

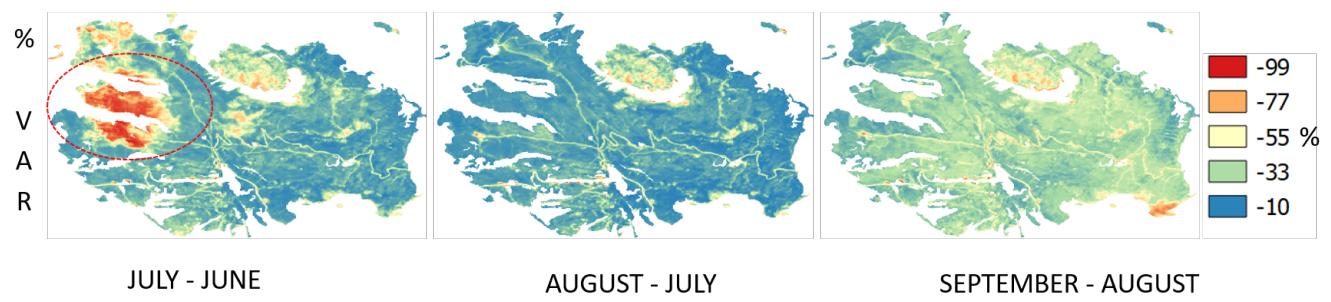

Figure 4. Monthly representation of Paneveggio NDVI \% variations maps in Summer 2020. Images from left to right, respectively, represent the percentage variation between June-July, July-August, and August-September.

The obtained NDVI maps (Figure 5, second row) depict the spatial variability of the NDVI value for the considered months. 


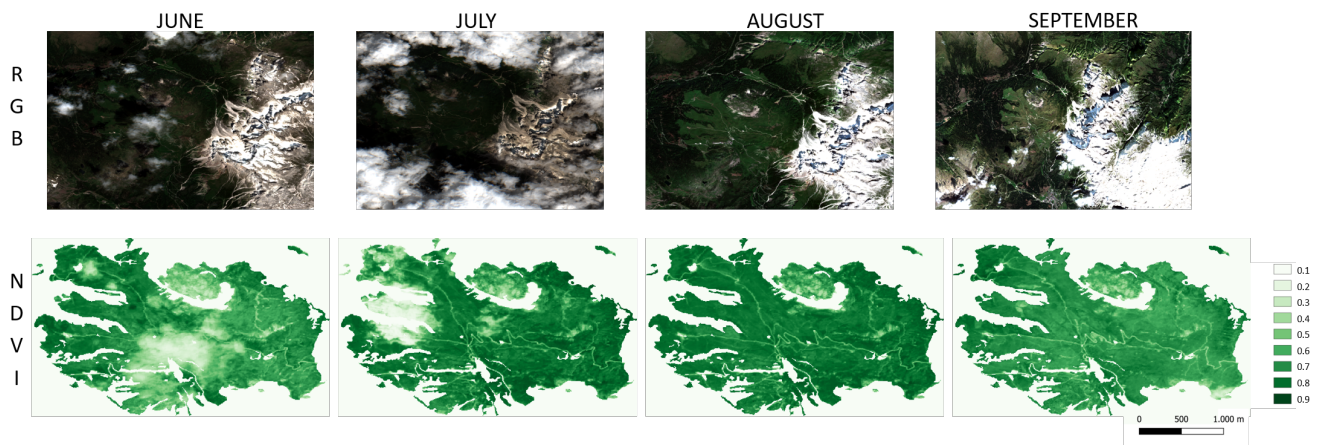

Figure 5. Monthly representation of Paneveggio NDVI maps in Summer 2020 (RGB image).

Figure 4 shows the relative percentage variation between one month and another represented as the trend of the index value for the same location. The variations in the index values can be attributable to factors internal to the pasture ecosystem, such as the variability due to the different life stages of the plants, nutrient availability, or to external factors. These, in particular, can be weather-climatic (humidity, temperature, radiation, accumulated rain, and extreme events, such as fires, hailstorms, and floods), or attributable to the action of grazing herbivores.

Other variations of a certain entity in the values of NDVI (and therefore of biomass of the grazing area) can be traced back to the time of forage harvesting. Extremevariation in index values variations can also be attributable to the presence of image-specific artifacts. For instance, the red oval in the first map of Figure 4 (July-June) highlights an extreme variability (in the range of 55-99\%) due to the presence of clouds in the original images for the same period. The rightmost map of Figure 4 shows an extensive overall variation of the NDVI values, ranging between $33 \%$ and $55 \%$, corresponding to the considerable variation of the biomass of the grazing area that occurred between August and September at the time of the final harvest.

\subsection{AS4-Surface Urban Heat Island Effect Monitoring}

The phenomenon of urban Heat Islands (UHIs) affects urban areas and it is caused by urbanization and industrialization processes, representing one of the main anthropogenic alterations of Earth environments [88]. UHIs are formed in the proximity of extensive impervious surfaces, which tend to have a higher temperature than the surrounding rural areas with the same geographical features.

Structures, such as buildings, roads, and other infrastructure, re-emit the sun's heat more than natural landscapes, such as forests and water bodies, thus becoming "islands" of higher temperatures relative to outlying areas. Heat islands can form under a variety of conditions, including during the day or night, in small or large cities, in suburban areas, in northern or southern climates, and in any season (https: / /www.epa.gov/heatislands/lear n-about-heat-islands\#_ftnref1, accessed on 10 November 2021).

Research predicts that the heat island effect will strengthen in the future as the structure, spatial extent, and population density of urban areas grow [88]. UHI effects can be analyzed either from air temperature, also known as Atmospheric Heat Islands, which are more intense at night or predawn and in the Winter, or from the land surface temperatures (LST), also known as Surface Heat Islands (SUHIs), which are more intense during the day and in the Summer [89].

The atmospheric UHIs are assessed with in situ sensors or model data, which provide air temperature information [90-92], while the SUHIs are assessed by airborne or satellite RS platforms [93-95].

\subsubsection{Objectives and Study Area}

Satellites detect thermal LST data, allowing the employment of such products for urban planning and monitoring of the high-island effect based on surface temperature [96]. The 
identification of UHI contributing and mitigating factors is an open challenge, addressed through urban development strategies and policies for making cities inclusive, safe, resilient, and sustainable; thus, the need to understand the UHI phenomenon has aroused increasing worldwide research interest since 2005 [33].

This AS aims at evaluating the presence of SUHIs during the summer season in the Genoa metropolitan area $\left[44^{\circ} 24^{\prime} 40^{\prime \prime} \mathrm{N}, 8^{\circ} 55^{\prime} 58^{\prime \prime} \mathrm{E}\right]$. Genoa, the capital of Liguria, with a population of about 800,000 inhabitants, is the largest and most densely populated urban agglomeration in the Region, and its territory, close to the Mediterranean Sea and the steep hills of the hinterland, over the centuries has undergone an upheaval of its natural land-form as a result of human activities, such as modifications of the drainage network, excavations, and filling, building and street constructions, which was particularly intense in the 1960s and 1970s [97].

The peculiar climate and orography that distinguish Genoa from other European cities, such as London, Athens, and Stockholm, whose UHI effects have already been studied through Copernicus S-3 images [35,93,98], prompted us to analyze the SUHI effect using Copernicus products.

\subsubsection{Workflow}

Copernicus LST images are retrieved by S-3, whose mission consists of two satellites (S-3A in orbit since 2016, S-3B since 2018) with a revisit time of one day over Europe, providing land surface parameters at $1 \mathrm{~km}^{2}$ grid [10,99].

We downloaded 40 S-3 images acquired between 21 June and 22 September 2020, with eight products (4-nights and 4-days) for June and September and twelve products (6-nights and 6-days) for July and August. To delimit the study area, we used the vector layers that describe the provincial boundaries and the contour lines provided by the Liguria geoportal (https://geoportal.regione.liguria.it/, accessed on 10 November 2021), that allows open access to the updated and structured catalog of geo-referenced regional maps data. Furthermore, for the determination of rural surfaces and rural areas, we used the CLC_18 map [100].

The images were processed with QGIS to compute the SUHI band, creating for each month the average daily and nightly LST raster of the AOI. The background rural mean temperature, i.e., the LST mean value of pixels covering rural areas, is retrieved in order to assess SUHI effect computed according to Equation (2).

$$
\text { SUHI = LST - Background Rural Temperature }
$$

Owing to Genoa's highly variable orography and proximity to the sea, the different areas of the municipality have different average temperatures due to the altitude thermal gradient, also considering the complex morphology in the distribution of urban agglomerations. Accordingly, we selected only the rural areas below a given elevation, to avoid considering temperature-affecting factors that are not pertinent to the purpose of the study.

Consistent with the boundaries of the administrative borders and the contour lines of the AOI, the selection of the areas from which to calculate the average background rural temperature was constrained by two criteria: (i) the first constrains the non-overlapping and non-adjacency with urban areas, as defined by CLC_18; (ii) the second constrains the altitude to values less than $140 \mathrm{~m}$ above sea level, which represents the altimetric belt where most of the urban agglomerates are present. For each month analyzed, we considered the same rural areas to derive the background rural temperature, thus obtaining maps of SUHI comparable to each other.

In Figure 6, we report the calculated SUHI effect maps for day (Figure 6a) and night (Figure 6b) in Summer 2020 that show higher temperatures in urban areas (up to 4 degrees during the day) than the surrounding rural areas. Daily and nightly seasonal patterns highlight differences due to the nature of the SUHI effect.

Active solar radiation on the Earth's surface increases the LST of particularly reflective surfaces, such as large urban areas during the daytime, thus raising maximum values. The 
nightly SUHI effect, as explained by Lu et al. [101], owing to the absence of active solar radiation, is less intense in terms of temperature variations but more widespread.

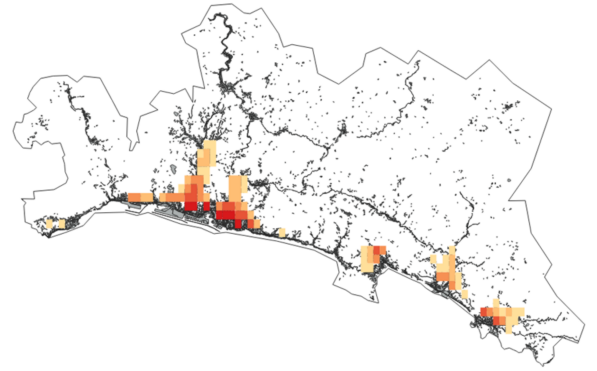

(a)

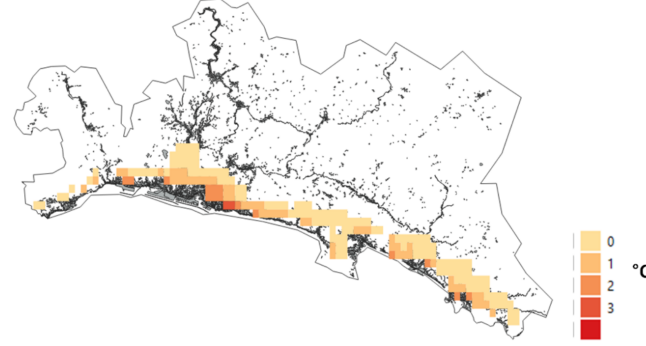

(b)

Figure 6. SUHI daily (a) and nightly (b) average for summer 2020 in the Genoa metropolitan area.

Figure 7 reports the SUHI trend along Genoa's coastline concerning urban and rural land-cover classes, from which the seasonal daily variability trend is detectable. The temperature profiles show that different types of soil cover have various thermal behaviors, with a positive temperature delta for the impervious surfaces.

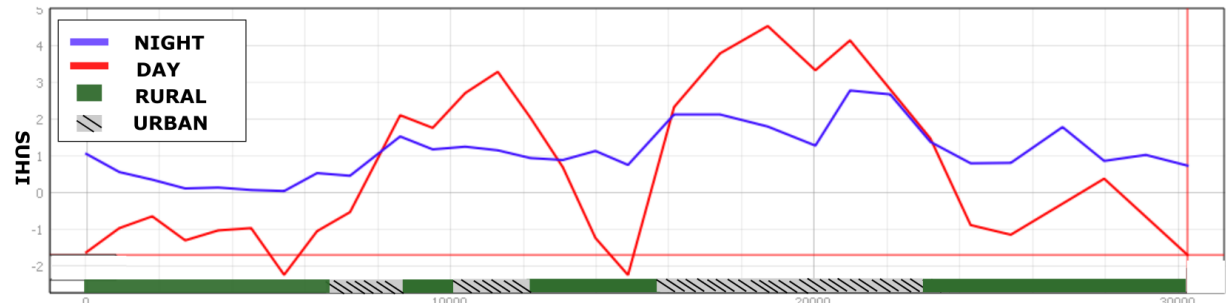

Figure 7. Daily (red line) and nightly (blue line) SUHI seasonal profile for summer 2020 along Genoa central coastline ( $1 \mathrm{~km}$ wide and $30 \mathrm{~km}$ long), in relation to urban (grey) and rural (green) land-cover classes (CLC_18) of the same profile.

\section{Findings and Discussion}

The design and development activities of the four ASs, combined with the analysis of the literature on downstream applications, have highlighted a series of practices, issues, and implementation options, which we believe are of common interest and that we present, to support end-users in the informed use of Copernicus ecosystem's resources and stimulating the development of innovative applications based on EO.

Furthermore, according to the analysis of the literature and our experience in the use and publication of open geospatial datasets, that highlighted their scarce usage, we supply some advice to the providers of these resources to improve their findability, access, and integration with Copernicus data.

\subsection{Recommendations for End-Users}

We observed that when developing an EO application, one must be aware that, according to one's own needs, it is necessary to choose the most appropriate available resources, even according to the spatial and temporal extent and resolution specific to the studied event. It is important to know and take into due account the task-specific aspects and any criticalities of the application scenario and its AOI.

Furthermore, it is often convenient to aggregate collections of subsequent images of the same AOI to build time series for monitoring some Earth phenomenon or even integrate Copernicus resources with other data sources for better analyzing some application scenarios. Finally, one must be aware of how to choose among the countless software and hardware tools available, concerning those mostappropriate to the level of technical skills and financial resources. 
In Table 3, we condensed these findings in the form of six recommendations for informed use of Copernicus resources, highlighting as many operational objectives and the various implementation options.

Table 3. Recommendations for informed use of Copernicus resources.

\begin{tabular}{|c|c|c|}
\hline Recommendation & Objective & Implementation Options \\
\hline Know your needs & $\begin{array}{l}\text { Chose the proper Copernicus data for the } \\
\text { specific application task }\end{array}$ & $\begin{array}{ll}\text { - } & \text { Sentinel products processing levels (e.g., } 0,1,2) \\
\text { - } & \text { Sentinel products vs. information provided by core } \\
\text { services } \\
\text { - } \quad \text { Sentinel products vs. other satellites sources Open } \\
\text { (e.g., Landsat-8) or commercial }\end{array}$ \\
\hline Size matters & $\begin{array}{l}\text { Identify the most suitable data source with } \\
\text { adequate temporal and spatial resolution for } \\
\text { the study of the phenomenon analyzed }\end{array}$ & $\begin{array}{l}\text { - Understand the proper spatial and temporal scale } \\
\text { of the phenomenon analysed (e.g., planetary, } \\
\text { synoptic, mesoscale, micro-scale) } \\
\text { - Evaluate spatial/temporal trade-off }\end{array}$ \\
\hline Do the right thing & $\begin{array}{l}\text { Understand the task-specific aspects and any } \\
\text { criticalities of your application scenario }\end{array}$ & $\begin{array}{l}\text { - } \begin{array}{l}\text { Select a proper sample set for the supervised } \\
\text { classification }\end{array} \\
\text { - } \quad \text { Consider the AOI borders for indices calculation } \\
\text { - } \quad \text { Mind the AOI-specific orography effects }\end{array}$ \\
\hline Tell a story & $\begin{array}{l}\text { Collect and process several Sentinel products } \\
\text { for change-detection practices and } \\
\text { monitoring in various sectors }\end{array}$ & $\begin{array}{l}\text { Large time intervals for climate change studies } \\
\text { (typically } 20 \text { to } 30 \text { years in length) } \\
\text { - } \quad \text { Faster dynamic phenomena (e.g., seasonal) } \\
\end{array}$ \\
\hline Mix and match & $\begin{array}{l}\text { Merge Copernicus products with } \\
\text { multitemporal, multiresolution, or } \\
\text { multisensor data for more effective EO } \\
\text { data-value chains }\end{array}$ & $\begin{array}{ll}\text { - } & \text { In-situ data (e.g., UAVs, drones, weather stations } \\
& \text { or other sensors) } \\
\text { - } & \text { Other satellite data sources } \\
\text { - } & \text { Model data (e.g hydrology or weather models) } \\
\text { - } & \text { Cartography (e.g., vector or raster layers from } \\
& \text { Open Geo-portals) }\end{array}$ \\
\hline Know Yourself & $\begin{array}{l}\text { Apply different approaches depending on } \\
\text { the levels of IT and RS skills, the degree of } \\
\text { geo-spatial data management competencies, } \\
\text { and the available computing infrastructure }\end{array}$ & $\begin{array}{ll}\text { - } & \text { Ability to process raw or high levels data } \\
\text { - } & \text { Suitable tools to download (e.g., Copernicus Open } \\
\text { Access Hub), processing (e.g., SNAP, R, MATLAB) } \\
\text { and results presentation (e.g., QGIS) } \\
\text { - } \quad \text { Availability of hw platforms on-premises, Cloud } \\
\text { solutions (RUS, DIAS) }\end{array}$ \\
\hline
\end{tabular}

\subsubsection{Copernicus Resources}

Developing an application scenario involves identifying the most suitable Copernicus resources, owing to users' needs and the requirements of the project to be deployed. Therefore, it is essential that users be aware of the variety of resources offered by the Copernicus ecosystem, understand their differences, and be able to distinguish them from other satellite product sources.

First, users must select the appropriate data pre-processing level for the specific application task. As previously mentioned, Copernicus satellites supply two pre-processing levels, each bringing different information. For instance, in AS1, AS2, and AS3, we selected S-2 L2 products, as they are corrected for atmospheric interference and are immediately usable for the study of phenomena occurring on the Earth's surface.

In AS4, we opted for the S-3 L2 products because they are particularly useful in the SUHI assessments scenario since the retrieval of the required band is performedby upstream data distribution through specific algorithms. Another reason for choosing the level 2 data provided by Copernicus for our AS was that the availability of high-level products is subject to geographic limitations. In fact, given the considerable costs of upstream processing of high-end satellite products in terms of technological resources used, national and international space organizations mainly carry out this process in the geographic areas where the interest of their user pool is oriented. 
AS4 provides a relevant example of this: while browsing the NASA USGS (https: / / earthexplorer.usgs.gov/, accessed on 10 November 2021) hub, we found ready-to-use LST data (Level 2, Collection 2 LST products). However, these products are not usable in our scenario concerning Genoa because they are supplied by NASA exclusively for the United States.

A second aspect to consider concerns the choice of adopting one of the Copernicus core services available. In fact, despite their relative ease of use, users should carefully evaluate the use of these resources since they may not always be suitable for their specific needs [5,31,102], as we noted, for instance, in developing AS1 and AS4. Indeed, for AS1, we decided to compute a new land-cover map by processing a S-2 L2A optical image rather than adopt the ready-to-use classification map provided by the CLMS service but dating back to 2018, because an updated map was deemed preferable for the scenario at hand.

In the AS4 case, we initially considered the use of two resources supplied by the C3S Climate Data Store, which are, at first glance, appropriate for studying assessment of the atmospheric UHI effect. The first is a collection of day and night UHI intensity time-series, relative to 100 European cities (https:/ /cds.climate.copernicus.eu/cdsapp\#!/Software/ap p-health-urban-heat-islands-current-climate?tab=app, accessed on 10 November 2021), including Genoa, supplied as annual maps showing the average summer and winter values, covering the period between 2008 and 2017 with a spatial resolution of $100 \mathrm{~m}$.

Since our study relates to 2020, we have not made use of this resource, preferring an updated data source. The second, UHI related, C3S resource evaluated is the ERA5 (https://cds.climate.copernicus.eu/cdsapp\#!/Dataset/reanalysis-era5-land?Tab=overvi ew, accessed on 10 November 2021) dataset that provides a temperature layer of $2 \mathrm{~m}(\mathrm{~T} 2 \mathrm{~m})$ on an hourly scale for the whole of Europe from 1981 to today. Although this resource is suitable for the atmospheric evaluation of the UHI effect, it is not usable for the calculation of SUHI.

Copernicus users need to be aware that other satellites products are available, as general practices suggest $[22,27,39,41]$, and to be able to discern when this data is preferable to Copernicus or could complement it [33]. For example, for our AS1, AS2, and AS3 scenarios, a possible alternative to Copernicus optical data is offered by Landsat 7 .

However, we excluded its use considering that it has a revisiting time of 16 days with a spatial resolution of $100 \mathrm{~m}$, hence as to the visible field, Landsat 7 has a Spatio-temporal resolution three times lower than S-2. Notwithstanding, Landsat 7 data may be suitable, for example, as in the case of the definition of long-term time series, and/or that cover longer observation periods since Landsat 7 was launched in 1999.

Alongside the open data made available by Copernicus and Landsat, there are several commercial initiatives that market satellite products of different types, such as optical, thermal, atmospheric fields, providing additional functionalities/resources due to exclusive agreements with customers. An example in the context of urban monitoring and air quality is the data provided by GHGSat (https:/ / www.ghgsat.com, accessed on 10 November 2021) satellites, which remotely measure and detect methane emissions at the facility level around the globe, and whose data can find applications in sectors, such as Oil and Gas (e.g., to optimize leak detection and repair activities), Landfills (e.g., gas collection system operational improvements), and Agriculture (e.g., dairy and beef cattle, other products sugar, additives, and rice).

\subsubsection{Spatial and Temporal Resolution}

The range of phenomena that occur, or can occur, at the planetary level is very spatially and temporally variable and, depending on the type of event, different scales can come into play, ranging from the size of the Earth over the years, up to areas limited to a few centimeters with temporal variations of the order of minutes or seconds.

The behaviors can be very different. Fluid dynamics and meteorology, studying a high percentage of Earth-system phenomena, divide these scales into classes within which the characteristics of motions are similar: the planetary scale, the synoptic scale (horizontal 
lengths varying from hundreds to thousands of kilometers, averaged overtimes in the order of 12-24 h), the mesoscale (a few tens to a few hundred kilometers with an hourly timestep), and the micro-scale for phenomena of lower-dimensional orders (up to hundreds of meters).

The 'scale analysis', i.e., the identification of the most suitable scale for the analysis and reproduction of a given phenomenon, is a practical exercise in many fields and applications [103]. To give an example, in forestry and agriculture, it may be necessary to study the weekly, monthly, seasonal, or inter-annual variations in the productivity of a pasture area in a given region (such as in AS3), or it is necessary to evaluate at what time of the week it is more appropriate to harvest specific fruit trees (such as in AS2).

Choosing which satellite source to adopt in a given scenario is subject to a spatial/temporal trade-off: often in the current satellite images, a high spatial resolution usually corresponds to a low temporal resolution. For instance, in AS4, when studying the SUHI effect, we initially evaluated using the thermal satellite images provided by Landsat- 8 Level 1, Collection 1, available since 2013, with a spatial resolution at $100 \mathrm{~m}$ for Europe, ten-times better than the ones of S-3.

However, Landsat- 8 has a revisit time on the study area of 15 days, with only daytime acquisitions, considerably less than S-3, which has a revisit cycle of less than one day at the middle latitudes, and with daytime and nighttime images that allow the assessment of day-night variations. For this reason, we opted for the higher number of observations available from S-3 than the more detailed ones offered by Landsat.

\subsubsection{Processing Task}

Even when the operative task of the processing phase is relatively simple, and its execution almost entirely supported by tools, such as SNAP (as in the case of map classification in AS1), the user needs to know the task-specific aspects and any criticalities potentially affecting the correctness of the processing execution outcomes. Considering the replicability of the operative tasks at the core of our four ASs (classification, vegetation index calculations, and identification of SUHI) in other application contexts, we summarize some of the salient factors that can discriminate their execution.

Map classification accuracy strongly depends on the prior available information, i.e., the training sample [104]; therefore, it is advisable to collect for each class a sample set covering the whole class-specific variability relating to the selected AOI. In AS1, performing the supervised classification with the SNAP K-nn classifier tool on the Osiglia S-2 RGB dam image, we first manually selected and prepared the dataset with at least 20 samples for each of the five classes.

In AS2 and AS3, we used S-2 L2A optical images to calculate the NDVI vegetation index of two different agricultural areas: vineyards and pastures. The vegetation indices are spectral transformations of two or more bands able to highlight the vegetation properties, recovered from the backward signal. The index calculation includes all the types of vegetation present in the $\mathrm{AOI}$ and, consequently, the invasive plants in the vicinity of the fields. Therefore, the reliability of a vegetation index, such as NDVI strictly depends on the ground distribution of the crop.

For AS2, we considered the rows of vines placed at a distance $>1 \mathrm{~m}$ from each other, while for AS3 a grazing area, i.e., a meadow, was considered. We noticed that the more homogeneous and dense a crop is on the ground (e.g., pastures), the more the index value is representative of the crop itself, with less interference from other plants (e.g., grass between the rows in AS2). For correctly interpreting the results, i.e., in the index values, we recommend evaluating the potential presence of interference due to non-agricultural vegetation in crops with discontinuous soil coverage.

When using satellite images, users must be aware of other characteristics and peculiarities of the AOI to avoid processing errors and misleading results. We found an example of this in AS4 when calculating the value of the SUHI effect starting from the LST band. In this case, the extraction of information on the SUHI band value from satellite images 
is relatively complex since Genoa has many mountainous reliefs in its metropolitan area, and the temperature is subject to an altitude gradient. It was, therefore, necessary to make a prior altimetric selection of the rural areas surrounding the urban districts to avoid a deviation of the results due to temperature and altimetric variations.

In AS4, the cross-information extraction between elevation lines and rural land cover areas allowed us to select rural areas with altimetric temperature variation $<1^{\circ}$. In similar cases, where the AOI has a complex orography or other specificities, users have to take these factors into account, which can increase the number of steps usually required in the processing phase compared to scenarios in which the morphology of the territory is more regular, making processing more time-consuming, especially in the presence of long time series.

\subsubsection{Time Series}

Despite being a relatively recent practice concerning Copernicus, the systematic use of satellite images for constructing time series lays the foundations for change-detection practices and monitoring in various sectors, avoiding carrying out extensive and expansive field data collection.

In particular, global phenomena, such as climate change, that have to be studied over long time intervals (measured from typically 20 to 30 years in length (https: / /www.ipcc.c h/sr15/chapter/chapter-3/, accessed on 10 November 2021) ) can benefit from this wide availability of satellite data. However, it is also possible to evaluate phenomena with a faster dynamic also considering variations during a single season. We discuss a baseline approach for the creation of time series in AS4 and AS3, respectively for analyzing SUHI effect and NDVI variations at a monthly scale.

In the agricultural sector [23,105-109] and the forestry sector [27], the health of crops was assessed respectively employing vegetation indices and variation of woodland cover in protected areas. Monitoring of the temporal trend of the forest cover, when affected by intense deforestation, can be depicted by comparing two inter-annual images, as performed by Palas et al. [30], who were able to determine a quantitative measure of the ecological impact of logging activities using S-2 images.

In the monitoring of urban areas, time series can inform about the variation in soil cover and the balance between anthropogenic and non-anthropogenic surfaces $[32,37,110]$.

The same process is considered in monitoring the use of renewable energy sources [44]. This aspect is equally valid in the monitoring of natural disasters [51-56,59-62] and emergencies $[57,59,61,111]$, where time-series are used to carry out precautionary assessments with a preventive approach in estimating the risk that a given event may or may not occur in the forecast. Romero et al. [58] adopted satellite products from inactive missions (i.e., ERS 1 and 2) for the creation of time series for monitoring coastlines, producing flood-risk maps, which consider catastrophic events with a longer return time, taking into account the history of the territory.

\subsubsection{Data Integration}

The abundance of geo-referred data collected by a wide array of sensors have made data integration an effective method for interpreting and analyzing Earth phenomena. This process can merge multitemporal, multiresolution, or multisensor data, and it is common to integrate satellite imagery with other data sources, for example, to compensate for those sources' low resolution in studying a small-scale phenomenon [21,39,40,45-50,112,113].

Copernicus data integration with in situ data-Data integration with in-situ data, i.e., proximal sensing, from various sources (e.g., UAVs, drones, weather stations or other sensors) is a common practice in the EO field [114]. For instance, it finds applications in sea and air-quality monitoring [39,40,45,47-50,112,113]. Van et al. [41] integrated Sentinel images with in situ ship-based observations made by water samples, for the retrieval of harmonised chlorophyll indicator maps to create an indicator displaying chlorophyll concentration in seawater. 
Bensoussan et al. [40] leveraged S-3 sea-surface temperature images for superficial temperature assessment in the Mediterranean sea, integrating meteorological, climatic, biological, and ecological parameters of Protected Areas. Despite the undoubted advantages, the integration with in situ data is not always without difficulties, as discussed, for example, by Palas et al. [30] in a forestry application integrating in situ observational data relating to "abatement sites" to validate the vegetation indices computed from S-2 products.

Copernicus data integration with other satellite data-Sentinel spatial resolution and revisit time offer an adequate coverage especially for Europe, since the acquisition frequency for satellites sensitive to clouds is a maximum of 5 days, with an average of six acquisitions per month, which, despite local peculiarities, can be used for monitoring purposes. Though, in some cases, coupling Copernicus resources with satellite products from other missions may be appropriate.

For instance, the $1 \mathrm{~km}^{2}$ grid-scale supplied by the S-3 LST band, is quite a coarse value for monitoring high-variability local phenomena such as SUHIs. This drawback may be solved by applying downscaling algorithms [33,115-117], which apply re-sampling steps, thus converting RS low-resolution images into high spatial resolution layers through the information extracted from higher spatial resolution thermal data such as the one supplied by LANDSAT-8, from which LST can be retrieved at a 100-m spatial resolution.

Similarly, integration can be performed with products of the same satellite constellation, as carried out by Shrestha et al. [38], between radar and optical images of S-1 and S-2 respectively, with urban-monitoring purposes.

Copernicus data integration with model data - In general, the use of data from remote or proximal sensing as input for models is a consolidated integration practice, as it allows to introduction of the values of variables directly recorded in the environment, producing outputs that are closer to the real conditions [118]. In meteorology and agriculture, integrating Copernicus and model data is becoming a common practice, especially concerning weather and atmospheric applications [21,43,45,57,111].

For instance, in AS1, we used the hydrological models TerraHidro and HAND $[75,77,119]$ to produce layers matching the classification map with a hydrological risk assessment. Data assimilation techniques combine observational data with output from a numerical model to produce a more precise estimate of the evolving state of the Earth system [50].

Copernicus data integration with cartography database-EO applications can also benefit from the integration of Copernicus data with local cartography and toponymy provided at various detail levels, in vector or raster format, by public administrations through their geoportal or websites or by the Copernicus services themselves.

For instance, in AS4, we used either Copernicus resources (i.e., the CLC_18 supplying a vector-based dataset with 44 land-cover and land-use classes) provided by the CLMS service and the maps (i.e., the shapefiles of the administrative boundaries and the contour lines of the Genoa metropolitan area) offered by the Liguria regional geoportal. As well, we used CLC_18 in AS2 for vineyard identification and the Paneveggio park shapefile to gather the pasture-areas borders for AS3, and couple them with the newly classified NDVI maps.

\subsubsection{Technological Know How}

Each phase of the workflow, from data selection to representation of the final results, can be carried out with different approaches, depending on the level of IT skills and technical knowledge of users. Conversely, we observed that even the adoption of readyto-use thematic resources such as the ones provided by Copernicus core services requires some understanding of the specific tools and (at least) an elementary degree of geo-spatial data management competencies. For instance, the use of CLC_18 in AS1, AS2, AS4, and of local cartography datasets in AS3, required basic notions of the reference systems and skills of GIS tools. 
Sentinel level 2 products contain informative "ready to use" bands, such as the S-3 LST band, which is provided with an accuracy of $1^{\circ} \mathrm{K}$ (even higher at night when the differential surface heating is absent (https: / / sentinels.copernicus.eu/web/sentinel/user-guides/sen tinel-3-slstr/overview / geophysical-measurements/land-surface-temperature, accessed on 10 November 2021) ). Conversely, LST information is provided implicitly in Landsat-8 data, thus requiring a more complex SUHI processing workflow.

In general, processing raw satellite data requires a good level of EO skills and knowledge, and, to this end, software, such as e-Cognition (https:/ / geospatial.trimble.com/pro ducts-and-solutions / ecognition, accessed on 10 November 2021) and SNAP allow users to manuallycompute the application parameters. However, these tools also provide thematic toolboxes, which facilitate user calculation of indices, or images corrections and classifications in "assisted" mode. For example, for optical images, the "thematic land processor" is available in SNAP, through which bands can be combined to obtain indices, such as NDVI, is very simple and user-friendly.

Data downloading via the Copernicus Open Access Hub-Guided User Interface is a valuable option for non-expert users and usually does not take much time. Even intermediate users may prefer a manual download rather than an automatic one, especially when the number of products to be downloaded is small, for instance, as in the case of the seasonal time-series construction we discussed in AS3 and AS4.

Some issues may arise when the products to be downloaded from the portal are transferred "offline", in the LTA. In fact, once offline, only one archived image can be downloaded every $30 \mathrm{~min}$. As an alternative solution, the LTA hub API (https: / / readth edocs.org/projects/sentinelsat/downloads/pdf/master, accessed on 10 November 2021) can be used. In this case, through implementing appropriate code scripts, for example, in Python, it is possible to download a batch of multiple images at once.

As we have seen, SNAP allows the creation of simple representations of the results, however, this is more than adequate for application scenarios, such as those we introduced (e.g., the generation of NDVI maps in AS2 and AS3). However, if further processing and integration with other data are required, an additional step through a GIS environment may be necessary.

We applied this procedure in the application scenarios that required the integration of Sentinel data with the resources of the local cartographic databases (e.g., AS2, AS3, and AS4). For further analyses on the achieved results (such as validation or comparison assessments), tools, such as MATLAB or R, are available, although requiring basic programming skills [120,121].

A non-trivial aspect when managing satellite products, often taking up a lot of disk space and requiring good computing power, is the hardware equipment available. For example, the creation of time series is usually a time- and space-consuming task (depending on the temporal and spatial extension of the study area considered), and the volume of data to be downloaded, stored, and processed can negatively affect the performance of machines not properly equipped.

For example, the SNAP guidelines recommend having at least $4 \mathrm{~Gb}$ of RAM and $10 \mathrm{~Gb}$ of free memory, although, in our experience, this basic equipment has not been free from performance problems. A valid alternative to overcome the limitations of on-premise resources is cloud-based technologies that leverage virtualized and distributed Information and Communication Technologies (ICT) solutions. The flexible, pay-per-use cloud approach has proven effective in both improving companies' business models [122] and supporting high-demanding e-science applications that require running complex simulations on a global scale [123,124].

Regarding the Copernicus world, a first option is the free and open Research And User Support (RUS (https: / / rus-copernicus.eu/portal, accessed on 10 November 2021)) cloud platform, which hosts a suite of pre-installed toolboxes on virtual machines allowing registered users to manage and process data derived from the Sentinels constellation. After 
a trial period, deemed necessary to become familiar with the Copernicus ecosystem, users should be able to continue their activities independently, outside RUS.

A mainly commercial option is provided by five Data and Information Access Services (DIAS) cloud platforms (https:/ / www.copernicus.eu/en/access-data/dias, accessed on 10 November 2021), i.e., Creodias (https:/ / creodias.eu, accessed on 10 November 2021), Mundi (https:/ / mundiwebservices.com, accessed on 10 November 2021), Onda (https: / / www.onda-dias.eu, accessed on 10 November 2021), Sobloo (https:/ / sobloo.eu, accessed on 10 November 2021), Wekeo (https: / / www.wekeo.eu, accessed on 10 November 2021), that supply a centralized access to Copernicus resources and processing tools.

Although, in general, they offer free access to Copernicus resources, their core business is the deployment of services and $\mathrm{EO}$ applications and tools via virtual machines, according to pay-per-use or package offers (https: / / earsc.org/ dias-comparison, accessed on 10 November 2021). Through these virtual machines, users may find the right solution to their needs in a ready-to-go environment with the required physical and software devices and without the burden to install and configure them.

Other than the access to Sentinel products and to a variable set of Copernicus core services, each DIAS offers its EO applications and processing tools, and can provide data collected by other satellite missions, both non-commercial (e.g., Mundi and Onda provide Landsat's collection) and commercial (e.g., Soblo provides Pleiades Very High-Resolution images).

\subsection{Advice for Data Providers}

The effective integration of Copernicus with other more specific spatial data sets, including open ones, is closely related to the degree of user skills. Indeed, thanks to the previous knowledge in this sector, we did not have particular difficulties in finding and accessing these data and incorporating them with Copernicus resources in our four ASs. However, such problems could arise for users of other application domains (away from RS and geodata).

Although a large amount of open geospatial datasets is now available to develop applications and to meet the information needs of citizens and organizations all around the world [125], in our previous work [9], we observed, based on an experimental evaluation of the usage of over 160,000 geospatial datasets belonging to six national and international Open Government Data (OGD) portals, that these data are highly underused.

Data and service providers, such as the intermediate users, that process satellite data and turn it into geo-information products (see Section 2), and public bodies that release geo-referred resources through OGD portals, should be able to understand the underlying causes of low data usage, to be capable implement effective countermeasures.

Among the main barriers that hinder the success of Open Data initiatives, the low information quality of data sets metadata is often mentioned [6]. The presence of good metadata, recommended among others by the World Wide Web Consortium (W3C) Data on the Web Best Practices (DWBP) (https://www.w3.org/TR/dwbp/, accessed on 10 November 2021) Working Group and by the findability, accessibility, interoperability, and reusability (FAIR) principles [126], is essential to help "human users and computer applications" understanding "the data as well as other important aspects that describe a dataset or a distribution" (DWBP Best Practice 1: Provide metadata).

By metadata, users can filter OGD portals by keyword search and features, such as theme category, data types, format, and license, for finding and accessing the datasets closer to their needs. To enable publishers to describe datasets and data services adequately, the W3C Dataset Exchange Working Group developed the last revision of the Data Catalog Vocabulary (DCAT) (https:/ /www.w3.org/TR/vocab-dcat-2/, accessed on 10 November 2021), providing a standard model and a Resource Description Framework (RDF) vocabulary, for facilitating the consumption and aggregation of metadata and increasing the discoverability of datasets and data services (i.e., "a collection of operations or API, which provides access to data"). 
Good quality metadata should also allow data providers to describe the provenance (i.e., the history or lineage) of the datasets (DWBP Best Practice 5: "Provide data provenance information") and their quality (DWBP Best Practice 6: Provide data quality information). The W3C Provenance Working Group defines Provenance as the "information about entities, activities, and people involved in producing a piece of data or thing, which can be used to form assessments about its quality, reliability, and trustworthiness".

The use of provenance metadata is also recommended by FAIR subprinciple R1.2: "(meta) data are associated with their provenance". Accordingly, to meet DWBP practices Five and Six, DCAT supplies "details for the ways of representing dataset provenance and quality". In the first case, DCAT suggests using the W3C Provenance Ontology (PROVO) (https:/ / www.w3.org/TR/prov-o, accessed on 10 November 2021), in the second to employ the W3C Data Quality Vocabulary (DQV) (https:/ / www.w3.org/TR/vocab-dqv/, accessed on 10 November 2021).

In our previous work, we exemplified the adoption of these two technologies by providing W3C compliant metadata to document the quality assessment of a set of eGovernment controlled vocabularies [127] and the provenance description of a collection of hydrographic datasets [79].

To assess the FAIRness of their resources, data providers can benefit from the framework designed by Wilkinson et al. [128] and by the 'FAIR Evaluator' (https://fairshar ing.github.io/FAIR-Evaluator-FrontEnd, accessed on 10 November 2021) tool they implemented, that provides a set of metrics to test the compliance of a Web resource with those principles. The tool implements "22 Maturity Indicators Tests", grouped by the four principles respectively, in eight (Findable), five (Accessible), seven (Interoperable), and two (Reusable).

By supplying the Globally Unique Identifier (GUID) of a given (Web) resource (e.g., the URI of a published dataset) to the tool, a data provider receives an assessment report summarizing the resource successes and failures for each of the 22 metrics.

\section{Conclusions}

The Copernicus program makes a primary contribution to the European Green Deal by sustaining the protection, conservation, and enhancement of the EU's natural capital. The availability of Copernicus open data, and its integration with other spatial data, opens new horizons to the downstream satellite applications industry, while supporting the European community's efforts to address increasingly pressing challenges of environmental and climate sustainability.

For this to happen, it is necessary to improve the awareness of end-usersconcerning the real opportunities offered by the Copernicus ecosystem and foster the dissemination of competencies and practical skills for its use in various Earth user segments. In pursuing these two objectives, the activities of the EO-UPTAKE project, which we summarized herein, highlight a set of practices that we deem convenient to share with those who want to begin implementing simple Copernicus-based application scenarios.

The paper presents a twofold contribution. First, to exemplify how end-users can benefit from the Copernicus ecosystem to develop applications of immediate practical use, we introduced four application scenarios, based on a typical Sentinel-based workflow scheme, in four user segments: Management of Natural Disasters, Agriculture, Forestry, and Urban Monitoring. For each scenario, we provided a reference framework that identifies the general objectives, presenting the specific ones concerning a well-defined area of study and detailing for each phase of the workflow what data, what tools, and what actions we performed to obtain the expected results.

These examples can be a spur and a guide to end users, particularly those with primary IT and RS skills, regarding the feasibility and replicability of similar scenarios in their specific contexts or for developing RS applications in other user-segments, such as those featured in related works. 
Our second contribution takes the form of a series of recommendations to end-users and advice to data providers regarding the informed use of Copernicus resources and the provision of geospatial products that we subsumed by the practices, problems, and implementation options derived from the four application scenarios, from the literature analysis and from our experience in using and publishing OD geospatial datasets.

To further strengthen the awareness of end-users about the opportunities offered by Copernicus and on the concrete possibilities of creating their analyses of the resources it offers, we first highlighted that the development of an EO application requires the user to carefully choose the most suitable among the various RS resources potentially available (Know your needs) while also bearing in mind the spatial and temporal extent of the studied event and the possible trade-offs (Size matter).

We indicated the importance for users of analyzing the task-specific aspects and any criticalities of their application scenario and its AOI and consequent acts (Do the right things). We also stressed the opportunity of aggregating image sequences of the same AOI to create time-series that are helpful to monitor the variations of terrestrial phenomena at different temporal scales (Tell a story) and the effectiveness of integrating the information resources of Copernicus with other data sources whether in situ, from models or from Open geo-portals to deepen the study of several application scenarios (Mix and match).

Last but not least, the user must be aware that there are many open-access or commercial software and hardware tools to choose from, based on their level of IT skills, the degree of know-how in geospatial data management, the available IT infrastructures, and, clearly, their finances (Know Yourself).

Regarding data and service providers, to cope with the underlying causes of low data usage and be capable of implementing effective countermeasures to better support users to find, access and incorporate these data with Copernicus resources, we outlined that, among the obstacles holding back the success of Open Data initiatives, is the low quality of datasets metadata.

To improve metadata quality and, hence, increase dataset usage, we advised data providers to adopt a series of practices and recommendations, such as those provided by the W3C and the FAIR principles, which emphasize the importance of including information on the provenance of the datasets and their quality in the metadata, using standard vocabularies, such as DCAT, PROV, and DQV. Finally, we provided a reference to the 'FAIR Evaluator' tool that assists data providers in verifying their data compliance with the FAIR principles.

For future work, we intend to move in two directions. On the one hand, there is the will to complete the picture of two ASs, namely AS2 and AS3, for integration with other data sources. In the first case, we foresee validating the NDVI maps produced through observations captured by a fleet of drones that are equipped with sensors for the analysis of the vines between the rows and also extending the study to another Ligurian AOI but characterized by rows located in inaccessible and mountainous areas.

In the case of AS3, the idea is to integrate the NDVI map with high-spatial-resolution data collected through biomass sampling in situ, near a "malga" (i.e., alpine hut) within the Paneveggio Park, for further calibration of the information of remote sensing through ground-truth data collection.

On the other hand, we plan to finish the implementation of two other ASs, which we have begun to examine. One concerns the identification of slope areas at risk of landslides caused by the presence of water leaks from underground utilities. The other aims to evaluate landfill gas emissions and slope consolidation.

These extensions and completions would allow expanding the range of application scenarios, thus, providing end-users with a more comprehensive picture of the opportunities offered by Copernicus. Indeed, the project initially planned these ASs extensions with the direct involvement of the partners. However, their actual implementation has been hampered and prevented due to the COVID-19 epidemic. 
Author Contributions: The authors contributed in the following way to the work reported in this paper and to its writing: conceptualization, Monica De Martino and Alfonso Quarati; methodology, Lorenza Apicella, Monica De Martino and Alfonso Quarati; software, Lorenza Apicella; investigation, Lorenza Apicella, Monica De Martino and Alfonso Quarati; writing_original draft preparation, Lorenza Apicella, Monica De Martino, Alfonso Quarati; writing-review and editing, Lorenza Apicella, Monica De Martino and Alfonso Quarati; supervision, Monica De Martino and Alfonso Quarati; project administration Monica De Martino; funding acquisition, Monica De Martino and Alfonso Quarati. All authors have read and agreed to the published version of the manuscript.

Funding: This research has been funded by the European Social Fund, Liguria Region 2014-2020, Axis 3, s.o. 10.5.

Acknowledgments: The authors wish to acknowledge all of those who contributed to the project development through scientific discussion, review, and data provision, stakeholder engagement, and facilitation: GISIG-Geographical Information Systems International Group, in Genoa (Italy), for his precious collaboration as a project partner, in particular, Roderic Molina and Silva Gorni. INPE-the National Institute for Space Research in Sao Jose dos Campos (Brazil), Info Solution S.p.A. in Genoa (Italy), and Dedagroup Public Services s.r.l. in Bologna (Italy) for supporting us in the definition of the application scenarios (respectively AS1, AS2, and AS3). A special thanks go to Loris Vescovo of Fondazione Edmund Mach, and the Highlander Project (https:/ / highlanderproject.eu/, accessed on 10 November 2021), who strongly supported us in identifying the AS3 scenario, presenting the problems of the AOI, and suggesting the idea of using the relative percentage variation between months of the NDVI index to evaluate the health of the pasture ecosystem.

Institutional Review Board Statement: Not applicable.

Informed Consent Statement: Not applicable.

Data Availability Statement: Not applicable.

Conflicts of Interest: The authors declare no conflict of interest.

\section{Abbreviations}

The following abbreviations are used in this manuscript:

$\begin{array}{ll}\text { AOI } & \text { Area of Interest } \\ \text { AS } & \text { Application Scenario } \\ \text { CAMS } & \text { Copernicus Atmosphere Monitoring Service } \\ \text { CEMS } & \text { Copernicus Emergency Management Service } \\ \text { CLMS } & \text { Copernicus Land Monitoring Service } \\ \text { CMEMS } & \text { Copernicus Marine Service } \\ \text { CSS } & \text { Copernicus Security Service } \\ \text { C3S } & \text { Copernicus Climate Change Service } \\ \text { DCAT } & \text { Data Catalog Vocabulary } \\ \text { DIAS } & \text { Data and Information Access Services } \\ \text { DQV } & \text { W3C Data Quality Vocabulary } \\ \text { DWBP } & \text { W3C Data on the Web Best Practices } \\ \text { EEA } & \text { European Agency for the Environment } \\ \text { EC } & \text { European Commission } \\ \text { ECMWF } & \text { European Centre for Medium-Range Weather Forecast } \\ \text { EGD } & \text { European Green Deal } \\ \text { EO } & \text { Earth Observation } \\ \text { ESA } & \text { European Space Agency } \\ \text { EUMETSAT } & \text { European Organisation for the Exploitation of Meteorological Satellite } \\ \text { FAIR } & \text { Findable, Accessible, Interoperable, Reusable } \\ \text { GUID } & \text { Globally Unique Identifier } \\ \text { HAND } & \text { Height Above the Nearest Drainage algorithm }\end{array}$




$\begin{array}{ll}\text { ICT } & \text { Information and Communication Technologies } \\ \text { IT } & \text { Information Technology } \\ \text { INPE } & \text { Instituto Nacional de Pesquisas Espaciais } \\ \text { L0 } & \text { Level-0 data } \\ \text { L1 } & \text { Level-1 data } \\ \text { L2 } & \text { Level-2 data } \\ \text { LST } & \text { Land Surface Temperatures } \\ \text { LTA } & \text { Long-Term Archive } \\ \text { MSI } & \text { HR Multi-Spectral Imagery } \\ \text { MTG-S } & \text { Spectrometer on Meteosat Third Generation Sounder } \\ \text { NASA } & \text { National Aeronautics and Space Administration } \\ \text { NDVI } & \text { Normalized Difference Vegetation Index } \\ \text { OGC } & \text { Open Geospatial Consortium } \\ \text { OLCI } & \text { Ocean and Land Color Instrument } \\ \text { OGD } & \text { Open Government Data } \\ \text { PROV-O } & \text { W3C Provenance Ontology } \\ \text { RDF } & \text { Resource Description Framework } \\ \text { RS } & \text { Remote Sensing } \\ \text { RUS } & \text { Research and User Support } \\ \text { SAFE } & \text { Standard Archive Format for Europe } \\ \text { SAR } & \text { Synthetic Aperture Radar } \\ \text { SMEs } & \text { Small and Medium Enterprises } \\ \text { SNAP } & \text { Sentinel Application Platform } \\ \text { SRTM-DEM } & \text { Shuttle Radar Topography Mission-Digital Elevation Model } \\ \text { SST } & \text { Superficial Sea Temperature } \\ \text { SUHIs } & \text { Surface Heat Islands } \\ \text { SLSTR } & \text { Surface Land Sea Temperature Radiometer } \\ \text { TROPOMI } & \text { TROPOspheric Monitoring Instrument } \\ \text { UHIs } & \text { Urban Heat Islands } \\ \text { UVN } & \text { Ultraviolet-Visible-Near-Infrared } \\ \text { VAS } & \text { Value-Added Services } \\ \text { W3C } & \text { World Wide Web Consortium } \\ & \end{array}$

\section{References}

1. EEA. The European Environment-State and Outlook 2020: Knowledge for Transition to a Sustainable Europe. 2019. Available online: https:/ / www.eea.europa.eu/soer/publications/soer-2020 (accessed on 10 November 2021).

2. EC. The European Green Deal. Final Version. 2019. Available online: https://ec.europa.eu/info/sites/default/files/europeangreen-deal-communication_en.pdf (accessed on 10 November 2021).

3. EC. General Union Environment Action Programme to 2030 2020. Available online: https:/ / ec.europa.eu/environment/pdf/8 EAP/2020/10/8EAP-draft.pdf (accessed on 10 November 2021).

4. EU Directorate-General for Internal Market, Industry, Entrepreneurship and SMEs. Space Strategy for Europe. 2016. Available online: https:/ / eur-lex.europa.eu/legal-content/EN/TXT/HTML/?uri=CELEX:52016DC0705\&from=EN (accessed on 10 November 2021).

5. EC. Fostering the Uptake of Copernicus and Space Applications. 2017. Available online: www.copernicus.eu/sites/default/files /Fostering_the_uptake_of_Copernicus_and_Space_applications_July2017.pdf (accessed on 10 November 2021).

6. Quarati, A. Open Government Data: Usage trends and metadata quality. J. Inf. Sci. 2021, 1-24. [CrossRef]

7. Quarati, A.; De Martino, M. Open government data usage: A brief overview. In Proceedings of the the 23rd International Database Applications \& Engineering Symposium, IDEAS 2019, Athens, Greece, 10-12 June 2019; ACM: New York, NY, USA, 2019, pp. 1-8. [CrossRef]

8. Quarati, A.; Raffaghelli, J.E. Do researchers use open research data? Exploring the relationships between usage trends and metadata quality across scientific disciplines from the Figshare case. J. Inf. Sci. 2020, 1-26. [CrossRef]

9. Quarati, A.; De Martino, M. Geospatial Open Data Usage and Metadata Quality. ISPRS Int. J. -Geo-Inf. 2021, 10, 30. [CrossRef]

10. Cheval, S.; Micu, D.; Dumitrescu, A.; Irimescu, A.; Frighenciu, M.; Ioja, C.; Tadose, N.C.; Davidescu, S.; Antonescu, B. Meteorological and Ancillary Data Resources for Climate Research in Urban Areas. Climate 2020, 8, 37. [CrossRef]

11. Lacava, T.; Papalia, L.B.; Paradiso, I.F.; Proto, M.; Pergola, N. On the Barriers Limiting the Adoption of the Earth Observation Copernicus Data and Services and Their Integration with Non-Conventional (e.g., Citizen) Observations: The EU CoRdiNet Project Contribution. In Proceedings of the 22nd EGU General Assembly, Online, 4-8 May 2020. [CrossRef]

12. EEA. EEA-Eionet Strategy 2021-2030. Final Version. 2021. Available online: https://www.eea.europa.eu/publications/eea-eione t-strategy-2021-2030, (accessed on 10 November 2021). [CrossRef] 
13. PWC. Copernicus Ex-Ante Benefits Assessment, Final Report. 2017. Available online: https://www.copernicus.eu/sites/defaul t/files/2018-10/Copernicus-Ex-Ante-Final-Report_0_0.pdf (accessed on 10 November 2021).

14. PWC. Copernicus Market Report. 2019. Available online: https://www.copernicus.eu/sites/default/files/PwC_Copernicus_Ma rket_Report_2019.pdf (accessed on 10 November 2021)..

15. PWC. Study to Examine the Socioeconomic Impact of Copernicus in the EU: Report on the Copernicus Downstream Sector and User Benefits, 2016. Available online: https://www.copernicus.eu/sites/default/files/2018-10/Copernicus_Report_Downstrea m_Sector_October_2016_0.pdf (accessed on 10 November 2021).

16. EC. Directorate-General for Internal Market, Industry, Entrepreneurship and SMEs. Copernicus User Uptake. Engaging with Public Authorities, the Private Sector and Civil Society: Final Version. Publications Office. 2016. Available online: https: / / data.europa.eu/doi/10.2873/927715 (accessed on 10 November 2021). [CrossRef]

17. Zeil, P.; Ourevitch, S.; Debien, A.; Pico, U. Copernicus User Uptake-Copernicus Relays and the Copernicus Academy. GI Forum-J. Geogr. Inf. Sci. 2017, 1, 253-259. [CrossRef]

18. Apicella, L.; Quarati, A.; Gorni, S.; Molina, R.; De Martino, M. Copernicus Users Uptake: An Overview of Downstream Applications. In Geomatics and Geospatial Technologies; Borgogno-Mondino, E., Zamperlin, P., Eds.; Springer International Publishing: Cham, Switzerland 2022; pp. 3-14.

19. Meier, J.; Mauser, W.; Hank, T.; Bach, H. Assessments on the impact of high-resolution-sensor pixel sizes for common agricultural policy and smart farming services in European regions. Comput. Electron. Agric. 2020, 169, 105205. [CrossRef]

20. Lilienthal, H.; Gerighausen, H.; Schnug, E. Agricultural remote sensing information for farmers in Germany. In Proceedings of the 14th International Conference on Precision Agriculture, Montreal, QC, Canada, 24-27 June 2018.

21. Drost, S.; Rieke, M.; Jirka, S.; Vogt, A.; Kirstein, V.R.; Lichtenplatzerstraße, U.; Wytzisk, A. An Event-Driven Architecture Based on Copernicus Satellite Data for Water Monitoring. In Proceedings of the AGILE 2019, Limassol, Cyprus, 17-20 June 2019.

22. Pulvirenti, L.; Squicciarino, G.; Cenci, L.; Boni, G.; Pierdicca, N.; Chini, M.; Versace, C.; Campanella, P. A surface soil moisture mapping service at national (Italian) scale based on Sentinel-1 data. Environ. Model. Softw. 2018, 102, 13-28. [CrossRef]

23. Wolanin, A.; Camps-Valls, G.; Gómez-Chova, L.; Mateo-García, G.; van der Tol, C.; Zhang, Y.; Guanter, L. Estimating crop primary productivity with Sentinel-2 and Landsat 8 using machine learning methods trained with radiative transfer simulations. Remote Sens. Environ. 2019, 225, 441-457. [CrossRef]

24. Vuolo, F.; Neuwirth, M.; Immitzer, M.; Atzberger, C.; Ng, W.T. How much does multi-temporal Sentinel-2 data improve crop type classification? Int. J. Appl. Earth Obs. Geoinf. 2018, 72, 122-130. [CrossRef]

25. Pelletier, C.; Valero, S.; Inglada, J.; Champion, N.; Dedieu, G. Assessing the robustness of Random Forests to map land cover with high resolution satellite image time series over large areas. Remote Sens. Environ. 2016, 187, 156-168. [CrossRef]

26. Borgogno-Mondino, E.; de Palma, L.; Novello, V. Investigating Sentinel 2 Multispectral Imagery Efficiency in Describing Spectral Response of Vineyards Covered with Plastic Sheets. Agronomy 2020, 10, 1909. [CrossRef]

27. Li, Z.; Chen, H.; White, J.C.; Wulder, M.A.; Hermosilla, T. Discriminating treed and non-treed wetlands in boreal ecosystems using time series Sentinel-1 data. Int. J. Appl. Earth Obs. Geoinf. 2020, 85, 1-17. [CrossRef]

28. Tavares, P.A.; Beltrão, N.E.S.; Guimarães, U.S.; Teodoro, A.C. Integration of Sentinel-1 and Sentinel-2 for Classification and LULC Mapping in the Urban Area of Belém, Eastern Brazilian Amazon. Sensors 2019, 19, 1140. [CrossRef] [PubMed]

29. Ottosen, T.B.; Petch, G.; Hanson, M.; Skjøth, C.A. Tree cover mapping based on Sentinel-2 images demonstrate high thematic accuracy in Europe. Int. J. Appl. Earth Obs. Geoinf. 2020, 84, 101947. [CrossRef] [PubMed]

30. Pałaś, K.W.; Zawadzki, J. Sentinel-2 Imagery Processing for Tree Logging Observations on the Białowieża Forest World Heritage Site. Forests 2020, 11, 857. [CrossRef]

31. Fonseca, A.; Ugille, J.P.; Michez, A.; Rodríguez-González, P.M.; Duarte, G.; Ferreira, M.T.; Fernandes, M.R. Assessing the Connectivity of Riparian Forests across a Gradient of Human Disturbance: The Potential of Copernicus "Riparian Zones" in Two Hydroregions. Forests 2021, 12, 674. [CrossRef]

32. Masson, V.; Heldens, W.; Bocher, E.; Bonhomme, M.; Bucher, B.; Burmeister, C.; de Munck, C.; Esch, T.; Hidalgo, J.; Kanani-Sühring, F.; et al. City-descriptive input data for urban climate models: Model requirements, data sources and challenges. Urban Climate 2020, 31, 100536. [CrossRef]

33. Zhou, D.; Xiao, J.; Bonafoni, S.; Berger, C.; Deilami, K.; Zhou, Y.; Frolking, S.; Yao, R.; Qiao, Z.; Sobrino, J.A. Satellite Remote Sensing of Surface Urban Heat Islands: Progress, Challenges, and Perspectives. Remote Sens. 2019, 11, 48. [CrossRef]

34. Shumilo, L.; Kussul, N.; Shelestov, A.; Korsunska, Y.; Yailymov, B. Sentinel-3 Urban Heat Island Monitoring and analysis for Kyiv Based on Vector Data. In Proceedings of the 2019 10th International Conference on Dependable Systems, Services and Technologies (DESSERT), Leeds, UK, 2-7 June 2019; pp. 131-135. [CrossRef]

35. Sobrino, J.A.; Irakulis, I. A methodology for comparing the surface urban heat island in selected urban agglomerations around the world from Sentinel-3 SLSTR data. Remote Sens. 2020, 12, 2052. [CrossRef]

36. Hidalgo García, D.; Arco Díaz, J. Modeling of the Urban Heat Island on local climatic zones of a city using Sentinel 3 images: Urban determining factors. Urban Clim. 2021, 37, 100840. [CrossRef]

37. Lefebvre, A.; Sannier, C.; Corpetti, T. Monitoring urban areas with Sentinel-2A data: Application to the update of the Copernicus high resolution layer imperviousness degree. Remote Sens. 2016, 8, 606. [CrossRef]

38. Shrestha, B.; Stephen, H.; Ahmad, S. Impervious Surfaces Mapping at City Scale by Fusion of Radar and Optical Data through a Random Forest Classifier. Remote Sens. 2021, 13, 40. [CrossRef] 
39. Staneva, J.; Behrens, A.; Gayer, G.; Aouf, L. Synergy between CMEMS products and newly available data from SENTINEL. J. Oper. Oceanogr. 2019, 12, S1-S123. [CrossRef]

40. Bensoussan, N.; Cebrian, E.; Dominici, J.M.; Kersting, D.K.; Kipson, S.; Kizilkaya, Z.; Ocana, O.; Peirache, M.; Zuberer, F.; Ledoux, J.B.; et al. Using CMEMS and the Mediterranean Marine Protected Areas sentinel network to track ocean warming effects in coastal areas. J. Oper. Oceanogr. 2019, 12, S1-S123. Available online: http://hdl.handle.net/10261/201832 (accessed on 10 November 2021).

41. Van der Zande, D.; Eleveld, M.; Lavigne, H.; Gohin, F.; Pardo, S.; Tilstone, G.; Blauw, A.; Markager, S.; Enserink, L. Joint Monitoring Programme of the EUtrophication of the NOrthSea with SATellite data user case. J. Oper. Oceanogr. 2019, 12, S56-S61.

42. Poursanidis, D.; Traganos, D.; Reinartz, P.; Chrysoulakis, N. On the use of Sentinel-2 for coastal habitat mapping and satellitederived bathymetry estimation using downscaled coastal aerosol band. Int. J. Appl. Earth Obs. Geoinf. 2019, 80, 58-70. [CrossRef]

43. Minnett, P.; Alvera-Azcárate, A.; Chin, T.; Corlett, G.; Gentemann, C.; Karagali, I.; Li, X.; Marsouin, A.; Marullo, S.; Maturi, E.; et al. Half a century of satellite remote sensing of sea-surface temperature. Remote Sens. Environ. 2019, 233, 111366. [CrossRef]

44. Morin, S.; Abegg, B.; Demiroglu, O.C.; Pons, M.; Weber, F.; Hoppler, A.A.; Francois, H.; George, E.; Soubeyroux, J.M.; Samacoïts, R.; et al. The mountain component of the C3S-Sectoral Information Service European Tourism: Towards Pan-European Analysis and Projections of Natural and Managed Snow Conditions. In Proceedings of the International Snow Science Workshop, Innsbruck, Austria, 7-12 October 2018. [CrossRef]

45. Alfadda, A.; Rahman, S.; Pipattanasomporn, M. Solar irradiance forecast using aerosols measurements: A data driven approach. Sol. Energy 2018, 170, 924-939. [CrossRef]

46. Huijnen, V.; Wooster, M.J.; Kaiser, J.W.; Gaveau, D.L.; Flemming, J.; Parrington, M.; Inness, A.; Murdiyarso, D.; Main, B.; Van Weele, M. Fire carbon emissions over maritime southeast Asia in 2015 largest since 1997. Sci. Rep. 2016, 6, 26886. [CrossRef]

47. Baklanov, A.; Grimmond, C.S.B.; Carlson, D.; Terblanche, D.; Tang, X.; Bouchet, V.; Lee, B.; Langendijk, G.; Kolli, R.K.; Hovsepyan, A. From urban meteorology, climate and environment research to integrated city services. Urban Clim. 2018, 23, 330-341. [CrossRef]

48. Tchepel, O.; Monteiro, A.; Dias, D.; Gama, C.; Pina, N.; Rodrigues, J.; Ferreira, M.; Miranda, A. Urban aerosol assessment and forecast: Coimbra case study. Atmos. Pollut. Res. 2020, 11, 1155-1164. [CrossRef]

49. de Blas, M.; Ibáñez, P.; García, J.A.; Gómez, M.C.; Navazo, M.; Alonso, L.; Durana, N.; Iza, J.; Gangoiti, G.; de Cámara, E.S Summertime high resolution variability of atmospheric formaldehyde and non-methane volatile organic compounds in a rural background area. Sci. Total Environ. 2019, 647, 862-877. [CrossRef]

50. Eskes, H.; Huijnen, V.; Arola, A.; Benedictow, A.; Blechschmidt, A.M.; Botek, E.; Boucher, O.; Bouarar, I.; Chabrillat, S.; Cuevas, E.; et al. Validation of reactive gases and aerosols in the MACC global analysis and forecast system. Geosci. Model Dev. 2015, 8, 3523-3543. [CrossRef]

51. Handwerger, A.L.; Huang, M.H.; Fielding, E.J.; Booth, A.M.; Bürgmann, R. A shift from drought to extreme rainfall drives a stable landslide to catastrophic failure. Sci. Rep. 2019, 9, 1-12. [CrossRef]

52. Lesko, M.; Papco, J.; Bakon, M.; Liscak, P. Monitoring of natural hazards in Slovakia by using of satellite radar interferometry Procedia Comput. Sci. 2018, 138, 374-381. [CrossRef]

53. Darvishi, M.; Schlögel, R.; Kofler, C.; Cuozzo, G.; Rutzinger, M.; Zieher, T.; Toschi, I.; Remondino, F.; Mejia-Aguilar, A.; Thiebes, B.; et al. Sentinel-1 and ground-based sensors for continuous monitoring of the Corvara Landslide (South Tyrol, Italy). Remote Sens. 2018, 10, 1781. [CrossRef]

54. Rouyet, L.; Lauknes, T.R.; Christiansen, H.H.; Strand, S.M.; Larsen, Y. Seasonal dynamics of a permafrost landscape, Adventdalen, Svalbard, investigated by InSAR. Remote Sens. Environ. 2019, 231, 111236. [CrossRef]

55. Carlà, T.; Intrieri, E.; Raspini, F.; Bardi, F.; Farina, P.; Ferretti, A.; Colombo, D.; Novali, F.; Casagli, N. Perspectives on the prediction of catastrophic slope failures from satellite InSAR. Sci. Rep. 2019, 9, 1-9. [CrossRef]

56. DeVries, B.; Huang, C.; Armston, J.; Huang, W.; Jones, J.W.; Lang, M.W. Rapid and robust monitoring of flood events using Sentinel-1 and Landsat data on the Google Earth Engine. Remote Sens. Environ. 2020, 240, 111664. [CrossRef]

57. Vitolo, C.; Napoli, C.D.; Giuseppe, F.D.; Cloke, H.L.; Pappenberger, F. Mapping combined wildfire and heat stress hazards to improve evidence-based decision making. Environ. Int. 2019, 127, 21-34. [CrossRef] [PubMed]

58. Alvan Romero, N.; Cigna, F.; Tapete, D. ERS-1/2 and Sentinel-1 SAR Data Mining for Flood Hazard and Risk Assessment in Lima, Peru. Appl. Sci. 2020, 10, 6598. [CrossRef]

59. Doxani, G.; Siachalou, S.; Mitraka, Z.; Patias, P. Decision making on disaster management in agriculture with Sentinel applications. Int. Arch. Photogramm. Remote Sens. Spat. Inf. Sci. 2019, 42, 121-126. [CrossRef]

60. Caballero, I.; Ruiz, J.; Navarro, G. Sentinel-2 Satellites Provide Near-Real Time Evaluation of Catastrophic Floods in the West Mediterranean. Water 2019, 11, 2499. [CrossRef]

61. Rossi, C.; Acerbo, F.; Ylinen, K.; Juga, I.; Nurmi, P.; Bosca, A.; Tarasconi, F.; Cristoforetti, M.; Alikadic, A. Early detection and information extraction for weather-induced floods using social media streams. Int. J. Disaster Risk Reduct. 2018, 30, 145-157. [CrossRef]

62. da Costa, R.T.; Manfreda, S.; Luzzi, V.; Samela, C.; Mazzoli, P.; Castellarin, A.; Bagli, S. A web application for hydrogeomorphic flood hazard mapping. Environ. Model. Softw. 2019, 118, 172-186. [CrossRef]

63. Filipponi, F. Sentinel-1 GRD Preprocessing Workflow. Proceedings 2019, 18, 11. [CrossRef] 
64. Belgiu, M.; Csillik, O. Sentinel-2 cropland mapping using pixel-based and object-based time-weighted dynamic time warping analysis. Remote Sens. Environ. 2018, 204, 509-523. [CrossRef]

65. Giuliani, G.; Mazzetti, P.; Santoro, M.; Nativi, S.; Van Bemmelen, J.; Colangeli, G.; Lehmann, A. Knowledge generation using satellite earth observations to support sustainable development goals (SDG): A use case on Land degradation. Int. J. Appl. Earth Obs. Geoinf. 2020, 88, 102068. [CrossRef]

66. Wasko, C.; Sharma, A. Global assessment of flood and storm extremes with increased temperatures. Sci. Rep. 2017, 7, 1-8. [CrossRef]

67. Peruccacci, S.; Brunetti, M.T.; Gariano, S.L.; Melillo, M.; Rossi, M.; Guzzetti, F. Rainfall thresholds for possible landslide occurrence in Italy. Geomorphology 2017, 290, 39-57. [CrossRef]

68. Brandolini, P.; Cevasco, A.; Firpo, M.; Robbiano, A.; Sacchini, A. Geo-hydrological risk management for civil protection purposes in the urban area of Genoa (Liguria, NW Italy). Nat. Hazards Earth Syst. Sci. 2012, 12, 943-959. [CrossRef]

69. Faccini, F.; Robbiano, A.; Sacchini, A. Geomorphic hazards and intense rainfall: The case study of the Recco Stream catchment (Eastern Liguria, Italy). Nat. Hazards Earth Syst. Sci. 2012, 12, 893-903. [CrossRef]

70. Petaccia, G.; Lai, C.G.; Milazzo, C.; Natale, L. The collapse of the Sella Zerbino gravity dam. Eng. Geol. 2016, 211, 39-49. [CrossRef] [PubMed]

71. Petaccia, G.; Natale, L. 1935 Sella Zerbino Dam-Break Case Revisited: A New Hydrologic and Hydraulic Analysis. J. Hydraul. Eng. 2020, 146, 05020005. [CrossRef]

72. Ciabatta, L.; Brocca, L.; Massari, C.; Moramarco, T.; Puca, S.; Rinollo, A.; Gabellani, S.; Wagner, W. Integration of Satellite Soil Moisture and Rainfall Observations over the Italian Territory. J. Hydrometeorol. 2015, 16, 1341-1355. [CrossRef]

73. Duda, R.; Hart, P. Pattern Classification and Scene Analysis; Wiley: New York, NY, USA, 1973; Volume 3. [CrossRef]

74. Büttner, G.; Feranec, J.; Jaffrain, G.; Mari, L.; Maucha, G.; Soukup, T. The CORINE land cover 2000 project. EARSeL eProceedings 2004, 3, 331-346.

75. Rosim, S.; Oliveira, J.d.F.; Jardim, A.C.; Namikawa, L.M.; Rennó, C.D. TerraHidro: A distributed hydrology modelling system with high quality drainage extraction. In Proceedings of the International Conference on Advanced Geographic Information Systems, Applications, and Services, Nice, France, 1 March 2013; Volume 5, pp. 161-167.

76. Rosim, S.; Namikawa, L.M.; de Freitas Oliveira, J.R.; De Martino, M.; Quarati, A. Workflow provenance metadata to enhance reuse of south america drainage datasets. In Proceedings of the 2018 International Conference on eDemocracy \& eGovernment (ICEDEG), Ambato, Ecuador, 4-6 April 2018; pp. 16-23.

77. Rennó, C.D.; Nobre, A.D.; Cuartas, L.A.; Soares, J.V.; Hodnett, M.G.; Tomasella, J. HAND, a new terrain descriptor using SRTM-DEM: Mapping terra-firme rainforest environments in Amazonia. Remote Sens. Environ. 2008, 112, 3469-3481. [CrossRef]

78. De Martino, M.; Rosim, S.; Quarati, A. Hydrographic Datasets in Open Government Data Portals: Mitigation of Reusability Issues Through Provenance Documentation. In MTSR International Conference 2019; Springer Nature Switzerland AG: Cham, Switzerland, 2019; Volume 1057, pp. 307-319. [CrossRef]

79. De Martino, M.; Quarati, A.; Rosim, S.; Namikawa, L.M. Documenting flooding areas calculation: A PROV approach. Int. J. Metadata, Semant. Ontol. 2021, 15, 50-59. [CrossRef]

80. Lobitz, B.; Johnson, L.; Hlavka, C.; Armstrong, R.; Bell, C. Grapevine Remote Sensing Analysis of Phylloxera Early Stress (GRAPES): Remote Sensing Analysis Summary; NASA Ames Research Center: Mountain View, CA, USA, 1997; pp. 1-36.

81. Huang, S.; Tang, L.; Hupy, J.P.; Wang, Y.; Shao, G. A commentary review on the use of normalized difference vegetation index (NDVI) in the era of popular remote sensing. J. For. Res. 2021, 32, 1-6. [CrossRef]

82. Segarra, J.; Buchaillot, M.L.; Araus, J.L.; Kefauver, S.C. Remote Sensing for Precision Agriculture: Sentinel-2 Improved Features and Applications. Agronomy 2020, 10, 641. [CrossRef]

83. Bannari, A.; Morin, D.; Bonn, F.; Huete, A.R. A review of vegetation indices. Remote Sens. Rev. 1995, 13, 95-120. [CrossRef]

84. Meyers, J.M.; Dokoozlian, N.; Ryan, C.; Bioni, C.; Vanden Heuvel, J.E. A New, Satellite NDVI-Based Sampling Protocol for Grape Maturation Monitoring. Remote Sens. 2020, 12, 1159. [CrossRef]

85. Churchill, A.C.; Zhang, H.; Fuller, K.J.; Amiji, B.; Anderson, I.C.; Barton, C.V.M.; Carrillo, Y.; Catunda, K.L.M.; Chandregowda, M.H.; Igwenagu, C.; et al. Pastures and Climate Extremes: Impacts of warming and drought on the productivity and resilience of key pasture species in a field experiment. bioRxiv 2020. [CrossRef]

86. Fernando, G.; Víctor, C. Pasture Monitoring Applying Normalized Difference Vegetation Index (NDVI) Time Series with Sentinel-2 and Landsat 8 Images, to Improve Milk Production at Santa Mónica Farm, Imbabura, Ecuador. In Computational Science and Its Applications-ICCSA 2020; Gervasi, O., Murgante, B., Misra, S.,; Garau, C., Blečić, I., Taniar, D., Apduhan, B.O., Rocha, A.M.A.C., Tarantino, E., Torre, C.M., et al., Eds.; Springer International Publishing: Cham, Switzerland, 2020; pp. 560-575. [CrossRef]

87. Clarke, D.; Litherland, A.; Mata, G.; Burling-Claridge, R. Pasture monitoring from space. In Proceedings of the South Island Dairy Event (SIDE) Conference, Invercargill, New Zealand, 26-28 June 2006; pp. 108-123.

88. Oke, T.R. The energetic basis of the urban heat island. Q. J. R. Meteorol. Soc. 1982, 108, 1-24. [CrossRef]

89. Schwarz, N.; Schlink, U.; Franck, U.; Grossmann, K. Relationship of land surface and air temperatures and its implications for quantifying urban heat island indicators-An application for the city of Leipzig (Germany). Ecol. Indic. 2012, 18, 693-704. [CrossRef] 
90. Nichol, J.E.; Fung, W.Y.; se Lam, K.; Wong, M.S. Urban heat island diagnosis using ASTER satellite images and 'in situ' air temperature. Atmos. Res. 2009, 94, 276-284. [CrossRef]

91. Dash, P.; Göttsche, F.M.; Olesen, F.S.; Fischer, H. Land surface temperature and emissivity estimation from passive sensor data: Theory and practice-current trends. Int. J. Remote Sens. 2002, 23, 2563-2594. [CrossRef]

92. Clay, R.; Guan, H.; Wild, N.; Bennett, J.; Vinodkumar.; Ewenz, C. Urban Heat Island traverses in the City of Adelaide, South Australia. Urban Clim. 2016, 17, 89-101. [CrossRef]

93. Ravanelli, R.; Nascetti, A.; Cirigliano, R.V.; Di Rico, C.; Leuzzi, G.; Monti, P.; Crespi, M. Monitoring the Impact of Land Cover Change on Surface Urban Heat Island through Google Earth Engine: Proposal of a Global Methodology, First Applications and Problems. Remote Sens. 2018, 10, 1488. [CrossRef]

94. Tran, H.; Uchihama, D.; Ochi, S.; Yasuoka, Y. Assessment with satellite data of the urban heat island effects in Asian mega cities. Int. J. Appl. Earth Obs. Geoinf. 2006, 8, 34-48. [CrossRef]

95. Zhao, X.; Yang, S.; Shen, S.; Hai, Y.; Fang, Y. Analyzing the relationship between urban heat island and land use/cover changes in Beijing using remote sensing images. In Remote Sensing and Modeling of Ecosystems for Sustainability VI; Gao, W., Jackson, T.J., Eds. International Society for Optics and Photonics, SPIE: San Diego, CA, USA, 2009; Volume 7454, pp. 320-329. [CrossRef]

96. Voogt, J.; Oke, T. Thermal remote sensing of urban climates. Remote Sens. Environ. 2003, 86, 370-384. [CrossRef]

97. Faccini, F.; Luino, F.; Paliaga, G.; Sacchini, A.; Turconi, L.; de Jong, C. Role of rainfall intensity and urban sprawl in the 2014 flash flood in Genoa City Bisagno catchment (Liguria, Italy). Appl. Geogr. 2018, 98, 224-241. [CrossRef]

98. Li, H.; Zhou, Y.; Li, X.; Meng, L.; Wang, X.; Wu, S.; Sodoudi, S. A new method to quantify surface urban heat island intensity. Sci. Total Environ. 2018, 624, 262-272. [CrossRef] [PubMed]

99. Donlon, C.; Berruti, B.; Buongiorno, A.; Ferreira, M.H.; Féménias, P.; Frerick, J.; Goryl, P.; Klein, U.; Laur, H.; Mavrocordatos, C.; et al. The Global Monitoring for Environment and Security (GMES) Sentinel-3 mission. Remote Sens. Environ. 2012, $120,37-57$. [CrossRef]

100. Apicella, L.; Quarati, A.; De Martino, M. Analysing the Surface Urban Heat Island Effect with Copernicus Data. In Proceedings of the 10th International Conference, Electronic Government and the Information SystemsPerspective (EGOVIS), Virtual, Event, 27-30 September 2021; pp. 61-72. [CrossRef]

101. Lu, L.; Weng, Q.; Xiao, D.; Guo, H.; Li, Q.; Hui, W. Spatiotemporal Variation of Surface Urban Heat Islands in Relation to Land Cover Composition and Configuration: A Multi-Scale Case Study of Xi'an, China. Remote Sens. 2020, 12, 2713. [CrossRef]

102. Ponomarenko, M.R.; Zelentsov, V.A. Forest monitoring and analysis based on Earth observation data services. IOP Conf. Ser. Earth Environ. Sci. 2021, 806, 012003. [CrossRef]

103. Wallace, J.M.; Hobbs, P.V. Atmospheric Science: An Introductory Survey; Elsevier: San Diego, CA, USA, 2006 ; Volume 92.

104. Munoz-Mari, J.; Bruzzone, L.; Camps-Valls, G. A Support Vector Domain Description Approach to Supervised Classification of Remote Sensing Images. IEEE Trans. Geosci. Remote Sens. 2007, 45, 2683-2692. [CrossRef]

105. Gomarasca, M.A.; Tornato, A.; Spizzichino, D.; Valentini, E.; Taramelli, A.; Satalino, G.; Vincini, M.; Boschetti, M.; Colombo, R.; Rossi, L.; et al. Sentinel for Applications in Agriculture. Int. Arch. Photogramm. Remote Sens. Spat. Inf. Sci. 2019, XLII-3/W6, 91-98. [CrossRef]

106. Cole, B.; Smith, G.; Balzter, H. Acceleration and fragmentation of CORINE land cover changes in the United Kingdom from 2006-2012 detected by Copernicus IMAGE2012 satellite data. Int. J. Appl. Earth Obs. Geoinf. 2018, 73, 107-122. [CrossRef]

107. Marco, E.; Herrmann, D.; Schwab, K.; Schweitzer, K.; Almengor, R.; Berndt, F.; Sommer, C.; Probeck, M. Improvement of existing and development of future copernicus land monitoring products-The ecolass project. ISPRS-Int. Arch. Photogramm. Remote Sens. Spat. Inf. Sci. 2019, XLII-2/W16, 201-208. [CrossRef]

108. Piedelobo, L.; Taramelli, A.; Schiavon, E.; Valentini, E.; Molina, J.L.; Xuan, A.; González-Aguilera, D. Assessment of green infrastructure in Riparian zones using copernicus programme. Remote Sens. 2019, 11, 2967. [CrossRef]

109. Verron, J.; Bonnefond, P.; Andersen, O.; Ardhuin, F.; Bergé-Nguyen, M.; Bhowmick, S.; Blumstein, D.; Boy, F.; Brodeau, L.; Crétaux J.F.; et al. The SARAL/AltiKa mission: A step forward to the future of altimetry. Adv. Space Res. 2020, 68, 808-828. [CrossRef]

110. Dong, J.; Metternicht, G.; Hostert, P.; Fensholt, R.; Chowdhury, R.R. Remote sensing and geospatial technologies in support of a normative land system science: Status and prospects. Curr. Opin. Environ. Sustain. 2019, 38, 44-52. [CrossRef]

111. van Hateren, T.; Sutanto, S.; Van Lanen, H. Evaluating skill and robustness of seasonal meteorological and hydrological drought forecasts at the catchment scale - Case Catalonia (Spain). Environ. Int. 2019, 133, 105206. [CrossRef] [PubMed]

112. García-Haro, F.J.; Campos-Taberner, M.; Muñoz-Marí, J.; Laparra, V.; Camacho, F.; Sánchez-Zapero, J.; Camps-Valls, G. Derivation of global vegetation biophysical parameters from EUMETSAT Polar System. ISPRS J. Photogramm. Remote Sens. 2018, 139, 57-74. [CrossRef]

113. Adame, J.; Notario, A.; Cuevas, C.; Lozano, A.; Yela, M.; Saiz-Lopez, A. Recent increase in NO2 levels in the southeast of the Iberian Peninsula. Sci. Total Environ. 2019, 693, 133587. [CrossRef] [PubMed]

114. Di Gennaro, S.F.; Dainelli, R.; Palliotti, A.; Toscano, P.; Matese, A. Sentinel-2 Validation for Spatial Variability Assessment in Overhead Trellis System Viticulture Versus UAV and Agronomic Data. Remote Sens. 2019, 11, 2573. [CrossRef]

115. Huang, B.; Wang, J.; Song, H.; Fu, D.; Wong, K. Generating High Spatiotemporal Resolution Land Surface Temperature for Urban Heat Island Monitoring. IEEE Geosci. Remote Sens. Lett. 2013, 10, 1011-1015. [CrossRef]

116. Bonafoni, S. Downscaling of Landsat and MODIS Land Surface Temperature Over the Heterogeneous Urban Area of Milan. IEEE J. Sel. Top. Appl. Earth Obs. Remote Sens. 2016, 9, 2019-2027. [CrossRef] 
117. Stathopoulou, M.; Cartalis, C. Downscaling AVHRR land surface temperatures for improved surface urban heat island intensity estimation. Remote Sens. Environ. 2009, 113, 2592-2605. [CrossRef]

118. Niell, A. Preliminary evaluation of atmospheric mapping functions based on numerical weather models. Phys. Chem. Earth Part A Solid Earth Geod. 2001, 26, 475-480. [CrossRef]

119. Johnson, J.M.; Munasinghe, D.; Eyelade, D.; Cohen, S. An integrated evaluation of the National Water Model (NWM)-Height Above Nearest Drainage (HAND) flood mapping methodology. Nat. Hazards Earth Syst. Sci. 2019, 19, 2405-2420. [CrossRef]

120. Jamali, A. Land use land cover mapping using advanced machine learning classifiers: A case study of Shiraz city, Iran. Earth Sci. Inform. 2020, 13, 1015-1030. [CrossRef]

121. Apicella, L.; Quarati, A.; Rosim, S.; De Martino, M. User Uptake of Copernicus Resources: A Use Case for Land Monitoring. In Proceedings of the 2021 IEEE International Geoscience and Remote Sensing Symposium IGARSS, Brussels, Belgium, 11-16 July 2021; pp. 5688-5691. [CrossRef]

122. Quarati, A.; D’Agostino, D.; Galizia, A.; Mangini, M.; Clematis, A. Delivering cloud services with QoS requirements: An opportunity for ICT SMEs. In Proceedings of the International Conference on Grid Economics and Business Models, Berlin, Germany, 27-28 November 2012, pp. 197-211. [CrossRef]

123. Quarati, A.; Danovaro, E.; Galizia, A.; Clematis, A.; D'Agostino, D.; Parodi, A. Scheduling strategies for enabling meteorological simulation on hybrid clouds. J. Comput. Appl. Math. 2015, 273, 438-451. [CrossRef]

124. Yao, X.; Li, G.; Xia, J.; Ben, J.; Cao, Q.; Zhao, L.; Ma, Y.; Zhang, L.; Zhu, D. Enabling the Big Earth Observation Data via Cloud Computing and DGGS: Opportunities and Challenges. Remote Sens. 2020, 12, 62. [CrossRef]

125. Coetzee, S.; Ivánová, I.; Mitasova, H.; Brovelli, M. Open geospatial software and data: A review of the current state and a perspective into the future. ISPRS Int. J. Geo-Inf. 2020, 9, 90. [CrossRef]

126. Wilkinson, M.D.; Dumontier, M.; Aalbersberg, I.J.; Appleton, G.; Axton, M.; Baak, A.; Blomberg, N.; Boiten, J.W.; da Silva Santos, L.B.; Bourne, P.E.; et al. The FAIR Guiding Principles for scientific data management and stewardship. Sci. Data 2016, $3,160018$. [CrossRef]

127. Albertoni, R.; De Martino, M.; Quarati, A. Documenting Context-Based Quality Assessment of Controlled Vocabularies. IEEE Trans. Emerg. Top. Comput. 2021, 9, 144-160. [CrossRef]

128. Wilkinson, M.D.; Dumontier, M.; Sansone, S.A.; da Silva Santos, L.O.B.; Prieto, M.; Batista, D.; McQuilton, P.; Kuhn, T.; Rocca-Serra, P.; Crosas, M.; et al. Evaluating FAIR maturity through a scalable, automated, community-governed framework. Sci. Data 2019, 6, 1-12. [CrossRef] 